NBER WORKING PAPER SERIES

\title{
ARE PROTESTS GAMES OF STRATEGIC COMPLEMENTS OR SUBSTITUTES? EXPERIMENTAL EVIDENCE FROM HONG KONG'S DEMOCRACY MOVEMENT
}

\author{
Davide Cantoni \\ David Y. Yang \\ Noam Yuchtman \\ Y. Jane Zhang \\ Working Paper 23110 \\ http://www.nber.org/papers/w23110 \\ NATIONAL BUREAU OF ECONOMIC RESEARCH \\ 1050 Massachusetts Avenue \\ Cambridge, MA 02138 \\ January 2017
}

\begin{abstract}
Helpful and much appreciated suggestions, critiques and encouragement were provided by Ned Augenblick, Doug Bernheim, Arun Chandrasekhar, Ernesto Dal Bo, Matthew Gentzkow, Peter Lorentzen, Muriel Niederle, Torsten Persson, and many seminar and conference participants. Glen Ng and Meggy Wan provided excellent research assistance. Cantoni acknowledges financial support from the LMUexcellent Junior Researcher Fund and the European Research Council. The research described in this article was approved by the University of California-Berkeley Committee for Protection of Human Subjects, Protocol ID 2015-05-7571; by the Stanford University Institutional Review Board, Protocol 38481; by the University of Munich IRB, protocol 2016-11, and by the Hong Kong University of Science and Technology Human Participants Research Panel, submission 126. The experiment is registered on the AEA RCT registry with ID AEARCTR-0001423. The views expressed herein are those of the authors and do not necessarily reflect the views of the National Bureau of Economic Research.
\end{abstract}

NBER working papers are circulated for discussion and comment purposes. They have not been peer-reviewed or been subject to the review by the NBER Board of Directors that accompanies official NBER publications.

(C) 2017 by Davide Cantoni, David Y. Yang, Noam Yuchtman, and Y. Jane Zhang. All rights reserved. Short sections of text, not to exceed two paragraphs, may be quoted without explicit permission provided that full credit, including $\odot$ notice, is given to the source. 
Are Protests Games of Strategic Complements or Substitutes? Experimental Evidence from Hong Kong's Democracy Movement

Davide Cantoni, David Y. Yang, Noam Yuchtman, and Y. Jane Zhang

NBER Working Paper No. 23110

January 2017

JEL No. D74,D8,P0

\begin{abstract}
The decision to protest is strategic: an individual's participation is a function of her beliefs about others' turnout. Models of protest often assume strategic complementarity; however, the challenge of collective action suggests strategic substitutability. We conduct the first field experiment directly manipulating individuals' beliefs about others' protest participation, in the context of Hong Kong's pro-democracy movement. We elicit university students' planned participation in an upcoming protest and their prior beliefs about others' participation, in an incentivized manner. One day before the protest, we randomly provide a subset of subjects with truthful information about others' protest plans, and elicit posterior beliefs about protest turnout, again in an incentivized manner. This allows us to identify the causal effects of positively and negatively updated beliefs about others' protest participation on subjects' turnout. We consistently find evidence of strategic substitutes. Analysis of control group subjects and survey evidence reinforce our experimental findings.

Davide Cantoni

Seminar für Wirtschaftsgeschichte

University of Munich

80539 Munich

Germany

Davide.Cantoni@econ.lmu.de

David Y. Yang

Department of Economics

579 Serra Mall

Stanford University

Stanford, CA 94305

Noam Yuchtman

Haas School of Business

University of California, Berkeley

Berkeley, CA 94720

and NBER

yuchtman@haas.berkeley.edu

Y. Jane Zhang

Hong Kong University of Science and Technology

Division of Social Science

Clear Water Bay, Kowloon, HK

janezhang@ust.hk
\end{abstract}

dyang1@stanford.edu 


\section{Introduction}

What drives individuals' decisions to participate in political protests? At the core of social science research on protests lies a crucial strategic element: an individual's participation is shaped by beliefs about the participation of others. Much recent work assumes that the protest game is one of strategic complements: beliefs that others are more likely to turnout increase one's own likelihood of turnout ${ }^{1}$ Yet, incentives to free-ride on others' political collective action or to send a signal of one's "type" or "identity" could generate a game of strategic substitutes.2

While much theoretical work has been done on the strategic element of the protest decision, empirical evidence on the causal effect of beliefs regarding others' protest turnout on one's own is extremely limited ${ }^{3}$ We conduct the first field experiment directly manipulating individuals' beliefs about others' protest participation, studying how these beliefs shape one's own participation in a high-stakes context: Hong Kong's ongoing democratic, anti-authoritarian movement $4^{4}$

Credibly testing for strategic complementarity or substitutability in the protest decision has been hindered by three empirical obstacles. First, political movements have typically been studied ex post (e.g., Kuran, 1989, 1991, 1997; Opp and Gern, 1993; Lohmann, 1994). This not only generates selection issues - movements are generally studied after they have become large and successful - but also makes the prospective study of beliefs nearly impossible: belief elicitation would necessarily be retrospective and likely distorted by the realization of the political outcomes of interest.

Second, it is extremely difficult to exploit variation in beliefs to identify causal effects: naturallyoccurring variation is very likely to be endogenous with respect to behaviors of interest. Experimental variation, e.g., arising from an information treatment, runs into challenges from heterogeneous priors, which imply that the same information treatment can generate positive belief updating among one subset of the sample (i.e., those whose priors are below the information provided) and negative updating among another subset ${ }^{5}$ This means, for example, that even an effective intervention may produce average treatment effects on beliefs or on actions that appear to be a

\footnotetext{
${ }^{1}$ In a recent review article, Gehlbach et al. (2016, p. 579) go so far as to affirm that strategic complementarity "characterizes mass protests" (emphasis added). See also Granovetter (1978); Kuran (1989, 1991, 1997); Chwe (2000); de Mesquita (2010); Fearon (2011); Kricheli et al. (2011); Edmond (2013); Barbera and Jackson (2016).

${ }^{2}$ The political collective action problem was illustrated by Olson (1965). Akerlof and Kranton (2000) present an economic analysis of identity; Benabou and Tirole (2011); Besley et al. (2014); Jia and Persson (2016) present models in which adherence to a group's social norms may be a game of strategic substitutes.

3 González (2016) provides the best empirical analysis of "social" dimensions of the protest decision of which we are aware, exploiting rich information on students' social networks to provide convincing evidence of a positive peer effect on one's own protest participation. However, his analysis is unable to identify specific mechanisms underlying the peer effect. Specifically, it is difficult using the data he has available to isolate the effects of beliefs about others' turnout per se from other effects, such as information transmission or social learning regarding the quality of the protest. Recent empirical work on the causes and consequences of mass political movements includes Madestam et al. (2013); Yanagizawa-Drott (2014); DellaVigna et al. (2014); Acemoglu et al. (2014); Enikolopov et al. (2016).

${ }^{4}$ In Cantoni et al. (2016), we provide a complementary, descriptive study of the characteristics of supporters of Hong Kong's anti-authoritarian movement.

${ }^{5}$ See Coffman et al. (2015) for a theoretical analysis of the effects of information nudges.
} 
null result. The average effect would simply reflect heterogeneous treatment effects of opposite signs. Thus, experimental interventions aimed at manipulating beliefs require carefully measured priors (and ideally posteriors as well) to determine exactly how the treatment affects particular individuals' beliefs, and through beliefs, behavior.

Third, because movements demanding political rights from an authoritarian regime represent a natural, high-stakes context in which to study protest participation, researchers will often face challenges arising from working within politically unfriendly settings $\sqrt[6]{6}$ Elicited beliefs and actions may be distorted by fear or social stigma, making it difficult to study protesters credibly and in real time 7

We overcome each of these obstacles, as follows. First, Hong Kong's democracy movement (discussed in more detail below) is an ongoing, high-stakes political movement in its early stages, with uncertainty regarding the movement's ultimate success yet to be resolved. We study a movement that may grow to be overwhelming and successful in achieving political rights from Hong Kong's rulers in Beijing, or might be crushed ${ }^{8}$ Thus, we do not select this case on the movement's outcome. Because Hong Kong's democrats traditionally protest the rule of the Chinese Communist Party each Handover Day (July 1), there exists a known protest about which we can elicit beliefs prospectively, in real time.

Second, using a three-part online survey we conducted at the Hong Kong University of Science and Technology (HKUST), we are able to elicit the prior beliefs of over 1,200 university students regarding the protest turnout of their university classmates in the upcoming "July 1" protest, in an incentivized manner $9^{9}$ We are then able to provide an information treatment to a random subset and elicit posterior beliefs (again in an incentivized manner). Finally, we are able to elicit the

\footnotetext{
${ }^{6}$ The outcomes of these movements have shaped human societies and the wealth of nations: a large literature in the social sciences has studied the consequences of democracy for growth (e.g., Przeworski and Limongi. 1993: Przeworski et al. 2000: Gerring et al. 2005, Rodrik and Wacziarg, 2005, Persson and Tabellini. 2006, 2008. Papaioannou and Siourounis. 2008; Acemoglu and Robinson. 2012:|Bates et al. |2012: Meyersson.|2016 |Acemoglu et al. |2015) and other outcomes, e.g. health (Besley and Kudamatsu. 2006: Blaydes and Kayser. 2011). Relatedly, a growing theoretical and empirical literature studies the extension of the franchise (e.g., Acemoglu and Robinson, 2000, Lizzeri and Persico, 2004: Llavador and Oxoby, 2005: Acemoglu and Robinson, 2006: Aidt and Franck, 2012, 2015).This work typically considers aggregate behavior, rather than individual behavior, as we do.

${ }^{7}$ Indeed, analyses of political behavior in real time are more common in settings that are already politically free (e.g., Gerber et al. 2011, 2017). See Reny (2016) for a discussion on challenges facing social scientists in China.

${ }^{8}$ The eventual success or failure of the movement is likely to have repercussions throughout "Greater China" (and thus around the world) given concerns in Hong Kong, mainland China, as well as in Taiwan, over the increasingly authoritarian and nationalistic policies undertaken by the Chinese Communist Party. Our work contributes to a growing empirical literature on the political economy of contemporary Greater China: for example, Lorentzen (2013) highlights the central government's tolerance of certain types of protests; King et al. (2013) study information control policies that aim at suppressing collective actions; Martinez-Bravo et al. (2014) study the introduction of village elections in mainland China; Kung and Chen (2011), Jia (2014), and Fisman and Wang (forthcoming) study the effects of incentives within the Chinese bureaucracy; and, Cantoni et al. (forthcoming) study attempts by the Chinese Communist Party to shape mainland students' political attitudes through textbooks.

${ }^{9}$ The "July 1st March" is an annual protest rally that takes place in Hong Kong since the 1997 handover to the People's Republic of China. The protest became a major element of the broad democratic movement in Hong Kong since 2003, operates as a key channel for Hong Kong citizens to voice their demand for democracy, fight for universal suffrage, rights for minorities, protection of freedom of speech and a variety of other civil rights and political concerns.
} 
students' own protest participation in the protest.

Third, Hong Kong's institutions, at least for the moment, guarantee civil rights protection (including broad protections of the right to peaceably assemble and of political speech), allowing us to credibly elicit individuals' political beliefs and behavior. An illustration of Hong Kong's uniquely suitable environment for our analysis can be found in Freedom House's (2016) "Freedom in the World" report: in it, Hong Kong had the largest gap in the world between political rights and civil liberties: the civil liberties of Greece and the political rights of Zimbabwe ${ }^{10}$

The goal of our experimental design is to isolate the causal effect of variation in beliefs regarding others' protest participation on one's own protest participation. To do so, we provide a random subset of individuals in our sample truthful information intended to shift beliefs regarding others' protest participation. A challenge we face is that such information must be provided prior to the protest itself — before we know the actual protest decisions of others.

To solve this problem, one week before the protest, we collect information on individuals' beliefs about others' planned turnout, as well as individuals' beliefs about others' future actual turnout at the protest. One would imagine that these would be closely related, but crucially, we are able to elicit planned protest participation prior to the protest itself. This allows us to provide truthful information regarding others' planned participation, plausibly affecting beliefs regarding others' actual protest participation.

A day before the protest, we provide a random subset of individuals in our sample truthful information about the planned participation of their classmates. We estimate the "first stage" effect of information regarding others' planned participation on individuals' (posterior) beliefs regarding others' actual participation. Next, we estimate the "reduced form" effect of information regarding others' planned participation on individuals' own actual protest participation. Importantly, we split our analysis into two subsamples: those whose prior beliefs were below the true level of planned participation (whose beliefs regarding actual turnout, we expect, should be positively affected) and those whose prior beliefs were above the true level of planned participation (whose beliefs regarding actual turnout, we expect, should be positively affected) ${ }^{11}$

Our findings consistently point to our sample of Hong Kong students viewing the strategic component of their protest decision as being a game of strategic substitutes. Among subjects whose prior beliefs regarding others' planned participation were below the truth, the experimental provision of information regarding the true level of other subjects' planned participation has a significant and substantial, positive effect on beliefs about actual participation in the protest. Among these same subjects, information regarding the true level of others' planned participation has a

\footnotetext{
${ }^{10}$ Of course, this immediately raises the question of the external validity of our analysis. We discuss this issue in more detail below, but for now acknowledge that our analysis captures protest decisions in a particular movement, in a particular place and time, at a particular stage of a movement's evolution. Varying any one of these dimensions may affect our findings. Still, we believe that the analytic tools applied are very generalizable, and that our results can certainly inform thinking about a broad range of protest movements around the world.

${ }^{11}$ In addition to providing evidence on balance between treatment and control groups in the full experimental sample, we present evidence of balance within each of these subsamples. See Section 3
} 
significant negative effect on subjects' own turnout in the protest. Among subjects whose prior beliefs regarding others' planned participation were above the truth, the experimental provision of information regarding the true level of other subjects' planned participation has a significant and substantial, negative effect on beliefs about actual participation in the protest. Among these same subjects, information regarding the true level of others' planned participation has a significant positive effect on subjects' own turnout in the protest.

We additionally find non-experimental evidence indicating strategic substitutability in the protest decision: examining solely the naturally-occurring variation in beliefs about others' turnout among individuals in the control group, we again find that beliefs of greater turnout by others are associated with a lower likelihood of protest turnout.

We are able to address several questions about our analysis. First, using list experiments, we provide evidence that our experimental subjects are willing to truthfully report on potentially sensitive political attitudes related to their participation in the July 1 protest; this helps assuage concerns regarding our reliance on a self-reported measure of protest turnout (see Section 3.3).

Second, we can rule out a major threat to internal validity: the possibility that information about other subjects' turnout affected not only beliefs about others' protest participation, but also beliefs about the "quality" of the political movement itself. Such a confounding "social learning" effect, however, would produce the appearance of strategic complementarity, not the strategic substitutability that we find. A similar logic suggests that our findings are not driven by experimenter demand effects (see Section 5 ).

Third, we explore the external validity of our findings: we replicate our findings re-weighting our sample to match the HKUST student body; we also provide evidence of a negative correlation between participation in past protest events and optimistic beliefs regarding other subjects' adherence to anti-authoritarian views (again see Section 5). While we believe our findings have some external validity, we also highlight reasons why our context - an early-stage political movement, led by a committed core of activists - may be a very different game from larger scale movements. We think this is an important limitation on the external validity of our study, but also argue that early-stage movements - which may be unsuccessful, or may eventually evolve into larger scale movements - represent an important, understudied area of research.

We next, in Section 2, provide an overview on Hong Kong's ongoing democratic, anti-authoritarian movement. Then, in Section 3, we describe our experimental design. In Section 4, we present our main findings, and in Section 5 discuss their internal and external validity. Finally, in Section 6, we offer concluding thoughts. 


\section{Hong Kong's democracy movement}

Prior to 1997, Hong Kong was a British colony, with limited democratic political rights, but strong protections of civil liberties and respect for the rule of law ${ }^{12}$ On July 1, 1997, Hong Kong was returned to the People's Republic of China, to be ruled as a Special Administrative Region with its own quasi-constitution - the "Basic Law" - and a promise from China that its legal, economic, and social traditions would be respected and maintained until 2047, under a policy known as "one country, two systems." While the "Basic Law" and "one country, two systems" provide a structure for Hong Kong's political and legal institutions, there remain a great many details that have been bargained and battled over between the so-called "pan-democracy" and "pro-Beijing" camps and, of course, with Hong Kong's rulers in Beijing.

Hong Kong's ongoing democratic movement, expressed most dramatically in the "Umbrella Revolution" of 2014, has its roots in debate regarding the method of selection of Hong Kong's Chief Executive (the head of Hong Kong's government). Article 45 of the Basic Law of Hong Kong states the following:

The method for selecting the Chief Executive shall be specified in the light of the actual situation in the Hong Kong Special Administrative Region and in accordance with the principle of gradual and orderly progress. The ultimate aim is the selection of the Chief Executive by universal suffrage upon nomination by a broadly representative nominating committee in accordance with democratic procedures.

While indicating an ultimate aim of universal suffrage, the details of such an election are not specified. In particular, the Basic Law does not state when any election employing universal suffrage should take place, nor does it clarify the details of "nomination by a broadly representative nominating committee." From Hong Kong's return to China until today, the Chief Executive has been selected by an Election Committee, rather than by universal suffrage; currently, the Committee is composed of 1,200 members, and is widely seen as pro-Beijing.

In 2007, the Chinese government indicated a move toward universal suffrage in Hong Kong, with the Tenth National People's Congress stating: "[T]he election of the fifth Chief Executive of the Hong Kong Special Administrative Region in the year 2017 may be implemented by the method of universal suffrage." The Twelfth National People's Congress followed this in 2014 with the details of implementation: the proposed election mode would have allowed the citizens of Hong Kong a choice between two or three candidates, but these candidates would be selected by the same nominating committee as before ${ }^{13}$ Essentially, the people of Hong Kong would be given a choice set of two or three candidates - rather than one - selected by a pro-Beijing committee.

\footnotetext{
${ }^{12}$ This description of Hong Kong's anti-authoritarian movement closely follows that presented in Cantoni et al. (2016).

${ }^{13}$ Refer to http://www . scmp.com/news/hong-kong/article/1582245/full-text-npc-standing-committee-decis ion-hong-kong-2017-election, last accessed August 7, 2016.
} 
Meanwhile, members of Hong Kong's Democratic Camp organized to pressure the Chinese government to establish electoral institutions that adhered to international democratic norms, particularly regarding the nomination process for Chief Executive candidates. A group of citizens formed an organization known as "Occupy Central with Love and Peace" (OCLP), which threatened civil disobedience - an occupation of the Central District of Hong Kong — should Beijing not satisfy their demands.

In response to the very limited expansion of democratic rights offered by the Chinese proposal, the Hong Kong Federation of Students and the student political organization Scholarism organized a walkout on classes in late September 2014. Hong Kong police used tear gas on students and other democratic activists amassed in Central and Admiralty on September 28, 2014, which precipitated the much larger-scale "Umbrella Revolution," named for the ubiquitous umbrellas carried by participants. The Umbrella Revolution persisted for months, being slowly (and generally peacefully) cleared out by police by the end of December 2014. While the movement generated substantial press coverage around the world, it did not alter Chinese policy. The limited electoral reform proposal drafted by the Chinese Communist Party was sent to the Hong Kong LegCo for its approval, where it failed to reach the supermajority required for passage. Thus, in June 2015, the LegCo returned Hong Kong to the status quo ante of a Chief Executive appointed by the Election Committee.

Since June 2015, the democratic movement in Hong Kong has both fragmented and radicalized. While in 2014 efforts were coordinated around the demand for popular nomination of Chief Executive candidates and election via universal suffrage, Beijing's intransigence convinced significant components of the democratic movement that only a greater degree of self-rule - even independence - would ensure political rights and Hong Kong citizens' continued enjoyment of civil liberties and rule of law.

Recent encroachments on Hong Kong citizens' civil liberties, including the arrest (alleged kidnapping) of Hong Kong booksellers by the mainland Chinese government, have deepened Hong Kong citizens' fear of the Chinese Communist Party and their sense of a Hong Kong identity very much distinct from - even opposed to - that of mainland China. The result is that Hong Kong citizens and political parties are now much more loudly calling for independence or, more politically correctly, for "self determination." "Localist" violence has occasionally flared; new political parties, such as the student-led Demosistō, have formed and won seats in the 2016 LegCo election on platforms explicitly calling for self-determination 14

\footnotetext{
${ }^{14}$ Two legislators elected on a self-determination platform were recently removed from office by a ruling of the Chinese National People's Congress, foreshadowing future conflict.
} 


\section{Experimental design}

\subsection{Design overview}

Our experiment was conducted through a three-part email survey. The goal of our experimental design is to isolate the causal effect of variation in beliefs regarding others' protest participation on one's own protest participation. To do so, we provide a random subset of individuals in our sample truthful information intended to shift beliefs regarding others' protest participation. A challenge we face is that such information must be provided prior to the protest itself - before we know the actual protest decisions of others.

To solve this problem, one week before the protest, we collect information on individuals' beliefs about others' planned turnout, as well as individuals' beliefs about others' future actual turnout at the protest. One would imagine that these would be closely related, but crucially, we are able to elicit planned protest participation prior to the protest itself. This allows us to provide truthful information regarding others' planned participation, plausibly affecting beliefs regarding others' actual protest participation. We first estimate the "first stage" effect of information regarding others' planned participation on individuals' (posterior) beliefs regarding others' actual participation. Next, we estimate the "reduced form" effect of information treatment regarding others' planned participation on individuals' own actual protest participation. Putting together the first stage and the reduced form, we can estimate the effect of a change in beliefs about others' participation on one's own using two-stage least squares ${ }^{15}$

The broad outline of the design is as follows:

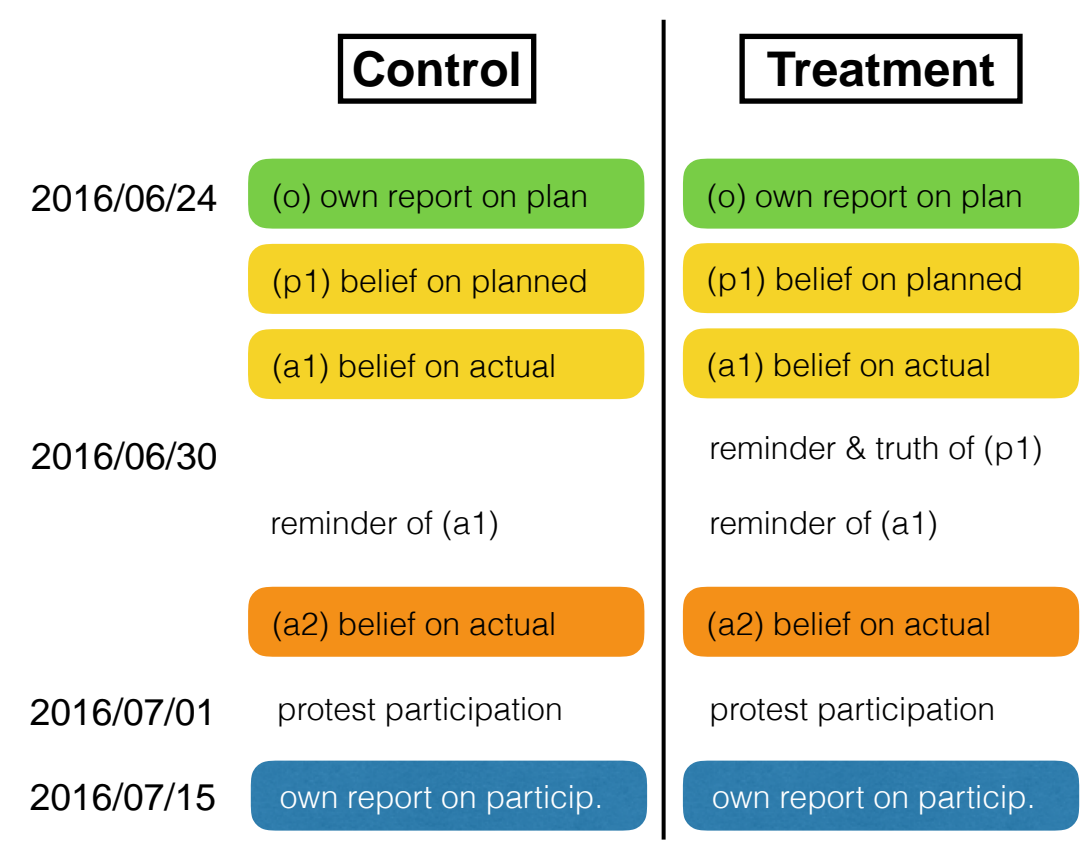

\footnotetext{
${ }^{15}$ We discuss this two-stage estimate, particularly the implied exclusion restriction, in more detail below.
} 
1. On June 24, 2016, we elicited subjects' own planned participation in the upcoming (planned) July 1, 2016, anti-authoritarian protest (known locally as the "July 1 March"). We also elicited (in an incentivized manner) subjects' beliefs regarding other subjects' planned protest participation. We refer to these as elicited priors regarding other subjects' planned participation. In the same survey, we elicited (again, in an incentivized manner) subjects' beliefs regarding other subjects' actual protest participation on July 1, 2016. We refer to these as elicited priors regarding other subjects' actual participation. Finally, we elicited (in an incentivized manner) subjects' beliefs regarding the total protest participation among all Hong Kong citizens on July 1, 2016. We refer to these as elicited priors regarding total actual turnout among all HK citizens.

2. On June 30, 2016, we provided a random subset of our experimental sample with information regarding the true level of planned protest participation. For both the information treatment group and the control group, we again elicited (in an incentivized manner) beliefs regarding other subjects' actual protest participation on July 1, 2016. We refer to these as elicited posteriors regarding other subjects' actual participation. Comparing posteriors between the treatment and control groups provides an estimate of the "first stage" relationship. We also elicited (in an incentivized manner) subjects' beliefs regarding the total protest participation among all Hong Kong citizens on July 1, 2016. We refer to these as posteriors regarding total actual turnout among HK citizens.

3. On July 15, 2016, we elicited subjects' participation in the July 1 protest. This provides us with our outcome variable of interest and comparing participation rates between the treatment and control groups provides an estimate of the "reduced form" relationship of interest. Self-reported July 1 protest participation is also the outcome in our two-stage estimates of the effects of beliefs regarding others' protest participation on one's own.

\subsection{Experimental sample}

Our sample of experimental subjects is drawn from the population of students at the Hong Kong University of Science and Technology. Studying a sample of students to understand protest participation is ideal given students' historic position at the center of anti-authoritarian, democratic movements. Students are certainly at the center of Hong Kong's democratic movement: among the leading groups in the Umbrella Revolution were Scholarism, a non-partisan organization of students, and the Hong Kong Federation of Students. Since the end of the Umbrella Revolution, Scholarism was disbanded; Joshua Wong and Nathan Law, the former leaders of Scholarism and the Hong Kong Federation of Students, respectively, formed a party called Demosistō, with the explicit aim of achieving Hong Kong's political self-determination.

In Part 1 of the study, we recruited participants on June 24, 2016, sending an email to the entire 
undergraduate population of the Hong Kong University of Science and Technology (HKUST) ${ }^{16}$ We received 1,744 completed surveys, achieving a response rate of 19.1\%. Among these, we focus on the 1,576 students who were either born in Hong Kong or moved there prior to high school (Hong Kong "natives") ${ }^{17}$ Part 1 of the experiment elicited students' political preferences, beliefs, attitudes, and planned and past political protest behavior. Because protests occur every year on Handover Day, July 1, we asked a series of questions specifically eliciting planned participation in the upcoming July 1 protest, as well as (prior) beliefs about turnout at the protest.

We paid students for their participation, and also provided additional payments as a function of their choices in incentivized games and in incentivized belief elicitations. On average, respondents received HKD 205, approximately US\$25, for completing this first survey. Our experimental intervention was conducted in Part 2 of the study, a very short online survey sent in an email on June 30, 2016, and completed by 1,303 Hong Kong native students 18 Along with the experimental intervention of interest (described below), this second survey elicited (posterior) beliefs about turnout in the following day's protest. Students received a payment of HKD 25 for completing the survey. Finally, in Part 3 of the study, we elicited students' participation in the July 1 protest of 2016 in a third online survey sent via email on July 15, 2016, and completed by 1,241 Hong Kong native students ${ }^{19}$ Students who completed Part 3 of the study received an additional payment of HKD 25.

In Table 1, columns 1 and 2, we present summary statistics for the 1,576 Hong Kong native students who completed Part 1 of the experiment. We then present summary statistics for the (mutually exclusive, exhaustive) subsets of students who: (a) completed only Part 1 of the study (273 students; see columns 3 and 4); (b) completed only Parts 1 and 2 (62 students; see columns 5 and 6); and, (c) completed all three parts (1,241 students; see columns 7 and 8). To test for systematic attrition of our sample after the assignment of treatment, we test for statistically significant differences between the subset of students who completed only Part 1 and the subset of students who completed all three parts of the study. In Table 1, column 9, one can see that there is very little evidence of systematic attrition post-treatment assignment in our study: two of 14 characteristics are marginally significantly different (at the $10 \%$ level) across groups 20

\footnotetext{
${ }^{16}$ All experimental materials were provided in English, the primary language of instruction at HKUST. Some bilingual support (i.e., materials provided in Chinese characters) is provided to clarify key terms.

${ }^{17}$ In Cantoni et al. (2016), we provide a comprehensive description of the survey conducted in Part 1 of this experiment, and a detailed analysis of students' political preferences.

${ }^{18}$ The full text of Part 2 of the study is reproduced in the Online Appendix A

${ }^{19}$ The full text of Part 3 of the study is reproduced in the Online Appendix A

${ }^{20}$ The sample of students who completed all three parts of the study is broadly similar to — though not precisely representative of - the broader HKUST student body on the dimensions of school of enrollment (i.e., students' broad academic area), gender, and cohort (see the Online Appendix, Table A.1. Note that all of our findings are robust to re-weighting our sample to match the composition of the HKUST student body; we discuss this further in Section 5 . below.
} 


\subsection{Elicitation of plans, beliefs, and actual protest participation}

\section{Part 1: Subjects' planned participation and prior beliefs}

In Part 1 of the study, on June 24, 2016, we elicited subjects' own planned participation in the upcoming July 1, 2016, anti-authoritarian protest, asking:

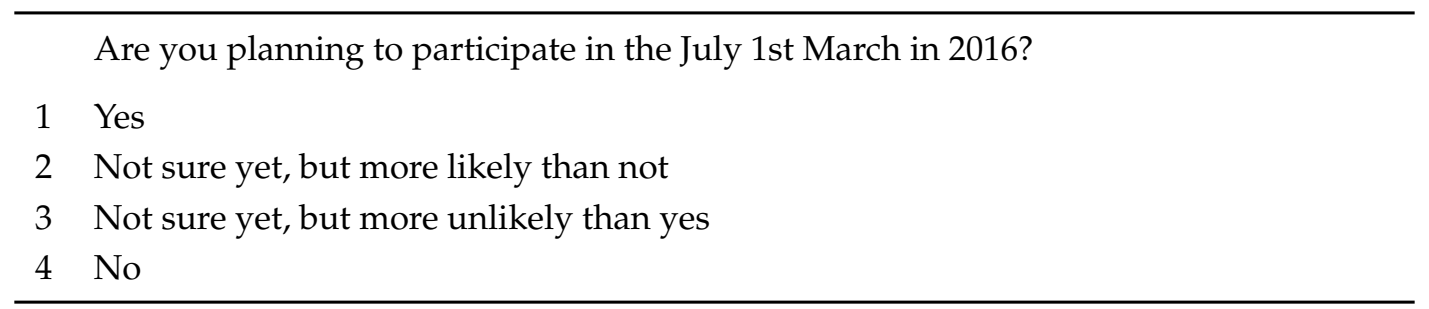

We next elicited (in an incentivized manner) subjects' beliefs regarding other subjects' planned protest participation (i.e., elicited priors regarding planned participation). Specifically, we asked:

Please guess what percentage of the participants from HKUST of this study plan to participate in the July 1st March in 2016 (answer either "Yes" or "Not sure yet, but more likely than not" to the above question on July 1st March in 2016).

If your guess is within 2 percentage points of the percent of students who actually answer either "Yes" or "Not sure yet, but more likely than not," you will earn a bonus payment of HKD 10.

In the same survey, we elicited (again, in an incentivized manner) subjects' beliefs regarding other subjects' actual protest participation on July 1, 2016 (i.e., elicited priors regarding actual participation). We asked:

Please guess what percentage of the participants from HKUST of this study will participate in the July 1st March in 2016.

If your guess is within 2 percentage points of the percent of students who actually participate, you will earn a bonus payment of HKD 10.

Responses in Part 1 indicated that 16.9\% of all subjects (including non-native Hong Kong students) planned to participate in the July 1 protest of 2016 (i.e., answered either "Yes" or "Not sure yet, but more likely than not" to the question regarding their plans for the upcoming July 1 protest). This is the number we use to provide "true" information regarding planned participation to experimental subjects (rounding to $17 \%$ ) ${ }^{21}$ The experimental sample's average prior belief regarding planned protest participation was quite close to the truth, at $15.8 \%$, but there was a great deal of variation around the truth (the standard deviation was also 15.8 percentage points).

\footnotetext{
${ }^{21}$ Among the Hong Kong native students who completed the study, whose protest behavior is our outcome of interest, $17.6 \%$ planned to participate.
} 
The sample's average prior belief regarding others' actual participation in the July 1 protest was slightly below beliefs about others' planned participation, at 13.9\%. In Figure 1, we present the distribution of subjects' prior beliefs regarding others' planned participation and regarding others' actual participation. One can see in the figure that these correspond quite closely, with the distribution of priors regarding actual participation shifted slightly to the left of the distribution of beliefs regarding planned participation.

\section{Part 2: The experimental intervention and posterior beliefs}

In Part 2 of the study, on June 30, 2016, we provided a random subset of our experimental sample with information regarding the true level of planned protest participation; we also elicited posterior beliefs regarding actual participation in the upcoming July 1 protest of 2016.

We randomly assigned two-thirds of subjects to the treatment group and one-third to the control group ${ }^{22}$ We present observable characteristics for the treatment and control groups and test for balance across groups in Table 2 , columns 1-3. One can see that the treatment and control groups are very similar in their observable characteristics, with only one of fourteen variables (altruism) statistically significantly different between groups at the 10 percent level or less ( $p$-value $=0.026) 23$

As discussed above, the impact of an information shock on beliefs, and thus behavior, should differ (likely having effects of opposite sign) depending on whether the information provided was above or below individuals' prior beliefs. We will thus conduct our analysis treating individuals with priors above and below the information treatment separately. Treatment assignment should have been orthogonal to individuals' prior beliefs; to make sure, we test for balance within the "Prior beliefs above truth" and "Prior beliefs below truth" subsets of our experimental sample. One can see in Table 2, columns 4-9, that treatment and control groups are balanced on observable characteristics within each of these subsets. Of 28 tests of differences between groups, only one (altruism among individuals with prior beliefs below the truth) is statistically significantly different between treatment and control at the 10 percent level or less ( $p$-value $=0.008$ ). Our findings of generally balanced treatment and control groups indicate successful randomization and support an interpretation of differences between treatment and control groups as indicative of causal effects of treatment 24

\footnotetext{
${ }^{22}$ The decision to assign more individuals to the treatment group was made taking into account that many subjects may have ignored Part 2 of the study, and thus effectively ended up in the control condition. Under such a scenario, we could have examined protest behavior among individuals who were actually treated and among individuals who were assigned to the control condition or who did note complete the survey in Part 2 of the study. In practice, the vast majority of subjects completed all three parts of the study, so the additional individuals in the treatment group were not strictly necessary.

${ }^{23}$ We will consider the effects of the imbalance in altruism in more detail below.

${ }^{24}$ It is important to note that variation in individuals' prior beliefs was not experimentally manipulated. In the Online Appendix, Table A.3 we present predictors of both individuals' own self-reported plans to participate in the protest as well as predictors of individuals' prior beliefs regarding other subjects' planned participation.
} 
Individuals in the treatment group - but not the control group - were reminded of their responses from Part 1 regarding other subjects' planned participation in the July 1 protest of 2016, and then told the actual level of other subjects' planned participation, as follows:

Recall that you guessed that [Part 1 response]\% of HKUST survey participants would plan to attend the July 1 March.

Based on last week's survey, the true percentage of survey participants who plan to attend the July 1 March is $\mathbf{1 7 \%}$.

All subjects (both treatment and control) were reminded of their responses from Part 1 regarding actual participation in the July 1 protest of 2016, as follows:

Remember that we offered you:

1 - A HKD 10 bonus payment for accurately guessing the percentage of HKUST survey

participants who would actually attend this July 1 March;

2 - An additional HKD 10 bonus payment for accurately guessing the total number of

Hong Kong citizens would actually attend this July 1 March.

In last week's survey, you guessed that:

1 - [Part 1 response] $\%$ of HKUST survey participants would attend this July 1 March;

2 - A total of [Part 1 response] Hong Kong citizens would attend this July 1 March.

All subjects were then given an opportunity to update their responses from Part 1:

Perhaps since then your views have changed.

We now ask you again to provide guesses about actual attendance of the July 1 March.

Instead of your guesses in the previous survey, we will use today's guesses to determine your bonus payment.

1 How many people in total do you think will participate in the

July 1st March in 2016?

If your guess is within $10 \%$ of what will be reported by the HKUPOP

after the July 1st March in 2016, then you will earn a bonus payment of HKD 10.

To give you a sense, according to HKUPOP's report, among the July 1st March that took place between 2003 and 2015:

The lowest attendance in a given year is: 17,000 (in 2008);

The highest attendance in a given year is: 462,000 (in 2003).

2 Please guess what percentage of the participants from HKUST of this study will participate in the July 1st March in 2016? 
If your guess is within 2 percentage points of the percent of students who actually participate, you will earn a bonus payment of HKD 10.

The experimental sample's average posterior belief regarding the percentage of other subjects who would actually participate in the July 1 protest was $14.5 \%$; the average posterior belief regarding total actual turnout among HK citizens was 143,856. In fact, the July 1 protest of 2016 was smaller than subjects expected: the protest was attended by $3 \%$ of experimental subjects, and only 26,000 people overall 25

\section{Part 3: Measuring protest participation}

In Part 3 of the study, on July 15, 2016, we elicited subjects' participation in the July 1 protest of 2016. We asked subjects:

Did you attend the July 12016 March?

A response of "yes" to this question is our measure of individuals' protest participation ${ }^{26}$

An important concern regarding our measure of protest participation is that experimental subjects may not report on their participation truthfully. This concern is particularly relevant in the context of an anti-authoritarian movement. However, there are several reasons to believe that self-reported protest turnout is a good measure in our context 27 First, as noted above, Hong Kong citizens' civil liberties remain largely protected by the "one country, two systems" institutions in place: there is a highly independent judiciary in place that protects citizens' rights to freedom of speech and assembly. Second, the particular protest that we study remained peaceful and did not result in any arrests. While subjects faced a risk of government crackdown on the protest ex ante, there was no concern regarding legal sanctions on participants two weeks after the protest, when subjects' protest participation was elicited. Third, for fear of government sanction to produce measurement error, it would need to be the case that subjects were willing to take the risk of attending a (very public) protest, but unwilling to tell us in a private survey that they did so. While this is possible (they may misperceive the observability of their protest choice and fear

\footnotetext{
${ }^{25}$ The smaller than expected protest was perhaps the result of an announcement on the morning of July 1 that the arrested and returned Hong Kong bookseller, Lam Wing-kee, would not lead the protest, as had been expected, out of fear for his safety. The Hong Kong Free Press headlined an article on June 28, “Organisers expect 100,000 to attend July 1 democracy rally led by bookseller and ex-prisoners of conscience" (https://goo.gl/kgDYr1, last accessed December 19, 2016). The same source headlined an article on July 1, "Returned HK bookseller will not lead July 1 democracy march after 'serious threat' to safety" (https://goo.gl/dHcR9b, last accessed December 19, 2016).

${ }^{26}$ We also ask a small number of follow-up questions: we asked subjects who reported attending the protest to indicate which of 28 groups' crowds they joined at the protest (we also gave them the option of "Others"). Next, we asked subjects for their impressions of the protest in an open-ended manner, subject to a 300 word maximum. Finally, we asked subjects about the number of their friends who attended the protest.

${ }^{27}$ This discussion of Hong Kong students' willingness to report their political attitudes and behavior truthfully closely follows that in Cantoni et al. (2016).
} 
putting their behavior on the record), it strikes us as unlikely.

As a more direct test of our experimental subjects' willingness to truthfully respond to politicallysensitive survey questions, in Part 1 of the study we elicited several key dimensions of political ideology that may be considered sensitive using "list experiments" (or, "Item Count Technique"; Raghavarao and Federer. 1979). The list experiment provides "cover" for the expression of possibly stigmatized attitudes, and allows one to estimate the prevalence of these attitudes at the population level. In addition, we adopt a modified version of the standard list experiment (Coffman et al., forthcoming) that appends "covered" elicitation with the traditional survey method (namely, direct question): the control group students in our list experiment setup (those who see $N$ statements instead of $N+1$ ) are asked the politically sensitive questions directly in the form of "yes" or "no." As a result, for each political attitude, we are able to compare the experimental sample's expressed adherence to that attitude in response to a direct question with the estimated adherence to that attitude based on our list experiment. We can then test whether there exists a distortion in the expression of a particular attitude in response to a direct question (e.g., due to stigma or fear).

In Table 3, we present the fraction of our sample expressing support for Hong Kong independence; who consider themselves Hong Kongese rather than Chinese; who have a favorable view of the ruling CCP; and, who support the use of violence in pursuit of Hong Kong's political rights. In the left-hand column, we simply present the population estimate of adherence to a political attitude based on direct questions. In the right-hand column, we show the difference between the estimate based on direct questions and the estimate based on the list experiment. One can see that for three of the political attitudes, there is no significant effect of providing respondents with "cover" for expressing their views; it is comforting that attitudes from supporting independence to expressing unfavorable views toward the ruling party are all expressed without significant fear in our setting. Only for the use of violence does the list experiment show a significant difference: it seems that many students in our sample would support the use of violence in order to achieve Hong Kong's political rights, but are afraid to say so when directly asked. That expressing such an extreme (and morally ambiguous) attitude is stigmatized is not surprising; indeed, finding a significant gap between direct questions and the list experiment on this dimension suggests that subjects do value the cover provided by the list experiment when it is needed - but it is not needed in response to political questions within the range of non-violent opposition to the Chinese Communist Party. 


\section{Main results}

\subsection{The first stage: effects on posterior beliefs}

We begin by presenting the effects of the information treatment on individuals' beliefs regarding actual participation in the July 1 protest - the "first stage." Our focus is on posterior beliefs regarding the percentage of other experimental subjects who would actually participate in the July 1 protest - this is the belief most directly linked to the information provided regarding subjects' planned participation. We will also present some evidence on posterior beliefs regarding total turnout among HK citizens.

The effect of the information treatment - informing the treatment group that $17 \%$ of experimental subjects planned to attend the protest - can be seen in the distributions of beliefs regarding subjects' actual participation, presented in Figure 2. One can see in the figure that prior beliefs regarding actual participation for the majority in the experimental sample were below $15 \%$; the median is at $10 \%$, and the distribution exhibits a long tail. One also sees in the figure that the distributions of posterior beliefs regarding actual participation look very different comparing the treatment and control groups. The control group's distribution of posteriors looks very much like the experimental sample's distribution of priors, but shifted slightly to the right. In contrast, the treatment group's posteriors are distributed much more tightly between $10 \%$ and $20 \% 28$

Given that the information we provided to subjects was above the prior beliefs of some (regarding planned participation) and below the prior beliefs of others, if subjects believed that the information provided was truthful, and updated their priors in the direction of the new information, one would expect to see a more compressed distribution of posteriors in the treatment group. Indeed, this is precisely what one can observe in Figure 2.

We next more closely examine the anticipated heterogeneous effects of the information treatment depending on subjects' prior beliefs, in Figure 3. In the figure, we present a binned scatter plot of the change in beliefs (posteriors minus priors) regarding other subjects' actual participation against subjects' priors regarding other subjects' planned participation. In the left-hand panel of the Figure 3, one can see that, as predicted, subjects in the treatment group with priors regarding planned participation below the information provided (recall that the true level of planned participation was around 17\%) all updated their beliefs regarding other subjects' actual participation positively. As predicted, all subjects in the treatment group with priors regarding planned participation above the information provided updated their beliefs regarding other subjects' actual participation negatively. Subjects in the treatment group with priors more distant from the information provided updated their beliefs more than those with priors closer to the information provided. In the right-hand panel of Figure 3, one can see that individuals in the control

\footnotetext{
${ }^{28} \mathrm{~A}$ Kolmogorov-Smirnov test of equality of posterior distributions between the treatment and control groups strongly rejects the null $(p<0.001)$.
} 
group with lower priors tended to update their beliefs positively, and vice versa - suggestive of mean reversion - but the changes in beliefs are tiny compared to those observed in the treatment group 29

Observing that belief updating in the treatment group systematically differs between subjects with priors above and below the information provided, we now study the first stage effects of the treatment splitting the experimental sample into groups with priors regarding planned participation above and below the true level of planned participation of $17 \%$. Recall that treatment and control groups are balanced on observable characteristics within each of these subsets (see Table 2, columns 4-9). In Figure 4, we present the prior and posterior beliefs regarding other subjects' actual participation for the treatment and control groups, split by priors regarding planned participation above and below the information treatment. One can see in the figure that there exists a strong first stage effect of the information treatment on beliefs regarding other subjects' participation. Among individuals with priors regarding other subjects' planned participation below the true level, there is a significantly greater increase in posteriors among the treatment group than among the control group. Among individuals with priors regarding other subjects' planned participation above the true level, there is a significantly greater decrease in posteriors among the treatment group than among the control group.

We next estimate regression models predicting changes in beliefs (posteriors minus priors) as a function of treatment status. In Table 4 . Panel A, column 1, one can see that among individuals with prior beliefs regarding planned participation of other subjects below the truth, treatment increases beliefs regarding other subjects' actual turnout by a statistically significant 4.5 percentage points. In column 2, one can see that among individuals with prior beliefs regarding planned participation of other subjects above the truth, treatment differentially decreases beliefs regarding other subjects' actual turnout by a statistically significant 10.2 percentage points. In Table 4 . Panel B, we add to the model estimated in Panel A controls for individual demographic characteristics as well as for the levels of individuals' prior beliefs regarding other subjects' planned participation 30 One can see that (consistent with successful randomization) including these controls does not meaningfully affect the estimated treatment effect.

We next pool individuals with prior beliefs regarding other subjects' planned participation both above and below the truth, but code the treatment variable as being equal to -1 for individuals with prior beliefs above the truth in order to make the treatment effect monotonic. In the pooled experimental sample we find that treatment changes beliefs "toward" the information provided by 9.8 percentage points (Table 4, Panel A, column 3). Including demographic controls and controlling for individuals' prior beliefs in Panel B has very little effect.

\footnotetext{
${ }^{29}$ The updating of beliefs among the control group may also result from information spilling over from the treatment group; such information spillovers would tend to bias estimated effects (in both the "first stage" and the "reduced form") toward zero.

${ }^{30}$ We control for priors regarding other subjects' planned participation because the sample is split on the level of this variable. Controlling for priors regarding other subjects' actual participation produces very similar estimates.
} 
One might believe that experimental subjects who update their beliefs regarding other subjects' turnout at the protest would also update their beliefs regarding the turnout of Hong Kong citizens more generally. We thus next examine the effect of the treatment on subjects' beliefs regarding protest turnout among the entire Hong Kong population. We replicate the specifications in Table 4, columns 1-3, but using as our outcome the change in beliefs (posteriors minus priors) regarding the total turnout in the July 1 protest of 2016. In Table 4 . columns 4-6, one can see that the treatment causes changes in beliefs regarding total protest size that match in sign the effects on beliefs regarding other subjects' actual turnout. While the point estimates are noisy (and only statistically significant in specifications pooling individuals with priors regarding other subjects' planned turnout both above and below the truth), they indicate that the treatment shifted beliefs regarding non-student citizens' turnout in the same direction as experimental subjects' turnout.

\subsection{The reduced form: effects on protest turnout}

We now turn to examining the effects of the information treatment on individuals' protest participation. As we did above, we split the experimental sample into two groups: first, subjects whose prior beliefs regarding other subjects' planned turnout was below the truth; and, second, subjects whose prior beliefs regarding other subjects' planned turnout was above the truth. In the previous section we saw that in the former group, the treatment increased beliefs regarding other subjects' turnout, while in the latter group, the treatment reduced beliefs regarding other subjects' turnout.

In Figure 5, we present turnout levels among subjects in the treatment and control groups in the two subsamples split according to priors. One can see in the figure that in the subsample whose priors were below the truth, the information treatment caused turnout to fall; in the subsample whose priors were above the truth, the information treatment caused turnout to rise. In other words, we find evidence that the protest decision is a negative function of beliefs regarding the turnout of others. It is worth emphasizing that this relationship is found in both the subsample with prior beliefs below the information provided, and the subsample with prior beliefs above. The protest game in this setting is one of strategic substitutes. 31

Interestingly, Figure 5 provides additional evidence consistent with the protest game being one of strategic substitutes: examining only the naturally-occurring variation in beliefs among the control group subjects, one sees that control group subjects with lower prior beliefs turn out more than control group subjects with greater priors. Of course, the non-experimental variation in beliefs is likely to be endogenous with respect to turnout: individuals more optimistic about protest turnout may be more supportive of the protest's aims, may have different information sets, etc. On the other hand, the relationship between naturally-formed beliefs and turnout is not

\footnotetext{
${ }^{31}$ One may be concerned that the lack of balance on subjects' altruism may affect our findings. In the Online Appendix, Figure A.1. we present graphs analogous to Figure 5. but disaggregating between subjects with altruism above and below the median. One can see that our findings are qualitatively the same for more altruistic and less altruistic subjects.
} 
an artifact of our experimental design.

In Figure 6, we show a binned scatter plot of control group subjects' protest participation against their posterior beliefs regarding other subjects' protest participation. One can see that greater beliefs regarding others' turnout are associated with lower protest turnout. Thus, both natural variation and experimental variation in beliefs indicate that Hong Kong students turnout to protest more when they believe that fewer others are going to turnout.

We next examine heterogeneity in the treatment effect associated with subjects' priors in a more disaggregated manner, regressing protest participation on the interaction between a treatment group dummy variable and 5-percentage-point bins of priors regarding other subjects' planned participation (as well as lower-order terms). In Figure 7, we present the estimated coefficients on the interaction terms as well as their $95 \%$ confidence intervals. One can see in the figure that the effect of the treatment on protest turnout was greatest among individuals whose priors were furthest from the information provided - precisely those subjects whose beliefs were most affected by the treatment (recall the results in Figure 3). These findings provide reassuring evidence of consistency between the first stage effects and the reduced form. We present evidence on heterogeneity in the treatment effect associated with subjects' priors in an even less parametric manner - presenting locally-weighted regression estimates of the treatment effect across subjects' priors - in Figure 8. One can again see that the treatment effects - negative for subjects with priors below the truth and positive for subjects with priors above the truth - are generally greatest among individuals whose priors were furthest from the truth.

\subsection{Two-stage estimates: the effects of beliefs on turnout}

Thus far we have shown that providing information regarding the true level of planned protest turnout among our experimental sample caused: (i) beliefs regarding actual turnout to change; and, (ii) subjects' own turnout to change, with beliefs and turnout moving in opposite directions. We next combine the two effects - first stage and reduced form — in a two-stage analysis that allows us to estimate the causal effect of a change in beliefs regarding actual turnout on one's own turnout. It is worth emphasizing that one should not interpret the two-stage estimates too literally: we have already shown that the information treatment affected beliefs regarding the turnout of both other experimental subjects and Hong Kong citizens more generally, so we cannot estimate the casual effect of precisely a one percentage point change in beliefs regarding other subjects' turnout ${ }^{32}$ With this caveat in mind, we still believe this exercise is instructive.

In Table 5, we present: (i) regression estimates of the "reduced form" effect - i.e., the effect of the treatment on subjects' own protest participation (Panel C); regression estimates of the "first stage" effect - i.e., the effect of the treatment on changes in beliefs (posteriors minus priors) re-

\footnotetext{
${ }^{32}$ In addition to concerns regarding precisely which beliefs may be causing a change in turnout, an even greater concern is that our treatment works through channels other than changing beliefs regarding protest turnout (e.g., social learning about the protest movement); we address this concern below.
} 
garding other subjects protest participation (Panel B); and, (iii) a two-stage estimate in which the treatment dummy variable is used as an instrument for beliefs regarding other subjects' protest participation in the first stage, and the experimentally-induced variation in beliefs is used to predict subjects' own protest turnout in the second stage (Panel A). As above, we split the sample according to whether subjects' priors regarding other subjects' planned participation were above or below the true value.

One can see in Table 5, Panels B and C, regression estimates that correspond to the results shown in Figures 4 and 5 . Individuals whose prior beliefs regarding other subjects' planned participation are below the true value update their beliefs positively in the treatment condition, and are less likely to participate in the protest; individuals whose prior beliefs regarding other subjects' planned participation are above the true value update their beliefs negatively in the treatment condition, and are more likely to participate in the protest. The treatment effects in both the first stage and the reduced form are statistically significant for each subsample, and they are robust to including controls for subjects' demographic characteristics and subjects' prior beliefs regarding others' planned protest participation.

In Table 5. Panel A, we present the two-stage estimates of the effects of beliefs regarding others' protest participation on one's own. For both subsamples we find a statistically significant effect of beliefs about others' participation, and the signs of the estimates indicate that protest participation is a game of strategic substitutes: more positive beliefs regarding others' participation are associated with lower protest turnout. While individuals with priors regarding planned turnout above the true value had their beliefs moved more on average, the change in protest participation associated with variation in posterior beliefs induced by the experimental treatment has very similar effects in the two subsamples: a one percentage point increase in beliefs regarding other subjects' protest participation is associated with around a one-half percentage point decrease in one's own likelihood of attending the protest. This is a large effect: a shock producing a one-standard deviation increase in posteriors (8-16 percentage points depending on the subsample) produces an estimated 3-10 percentage point reduction in individual protest turnout, between a 0.2 and 0.4 standard-deviation reduction.

\section{Discussion}

\subsection{Internal validity}

Our experimental design largely alleviates concerns regarding correlations between unobservable subject characteristics, treatment status, and outcomes. However, one might still wonder whether the treatment - information provided regarding the true fraction of experimental subjects planning to attend the upcoming protest — specifically affected protest participation through changing beliefs about others' participation. 
A first question is whether the updating of beliefs regarding other subjects' turnout was indicative of broader beliefs regarding protest turnout. While we do not observe beliefs regarding all possible "reference populations," we find that beliefs regarding the total Hong Kong population's turnout moved in the same direction as beliefs regarding other subjects, suggesting that our qualitative findings are sound (see Table 4, columns 4-6) ${ }^{33}$

One particularly important concern is that information regarding other subjects' protest plans not only affects beliefs about others' participation, but also affects beliefs about the political movement itself - as if the protest were a consumption good with uncertain quality. However, in this case, the standard social learning logic would suggest that positive updating of beliefs regarding the number of other subjects joining a protest should lead students to update positively about protest "quality." This would produce the appearance of strategic complementarity, not the strategic substitutability that we observe.

Another concern is that our results are driven by experimenter demand effects: perhaps subjects changed their behavior to conform to their perceptions of the experimenter's objectives. However, experimenter demand effects, too, would likely produce effects mimicking strategic complementarities - when the experimenter tells a subject that a behavior is more prevalent than the subject expected, the subject seems likely to assume that the experimenter is trying to induce that behavior.

In general it is difficult to construct alternative theories that would generate our findings: for example, confounding factors would need to systematically produce effects of the opposite sign depending on whether subjects' priors were above or below the information provided. One possibility is that the information treatment highlighted the gap between subjects' initial expectations and information collected by the experimenter. It is possible that (two weeks after the intervention) subjects systematically misreported their protest participation in an asymmetric manner, thus producing our findings. Beyond this story being rather convoluted, we are reassured that we find evidence of strategic substitutability in the protest game even in the absence of any experimental treatment. Simply examining naturally-occurring variation in beliefs (i.e., among our control group subjects) produces the same qualitative findings as found exploiting the experimental variation. We find evidence that the protest game is one of strategic substitutes even among individuals who received no message from the experimenter regarding other subjects' participation. This strongly suggests that our finding is not an artifact of the experimental design.

\footnotetext{
${ }^{33}$ We do not observe beliefs regarding another reference population of interest - subjects' close friends. It is possible that subjects view protest turnout as a game of strategic substitutes with respect to a broad student population and the population of Hong Kong as a whole, but view it as a game of strategic complements with their close friends. We leave the study of social networks with strong ties to future work.
} 


\subsection{External validity}

It is worth emphasizing that our findings arise from a specific sample of students engaged in a particular political movement at a particular stage in its evolution. That point conceded, it is worth exploring the external validity of our findings. A first question is whether they are likely to generalize to the broader population of HKUST. Although our experimental sample is not representative of the campus population, we can re-weight our observations to match the population on gender, cohort, and department. In the Online Appendix, Table A.2, we replicate Table 5, showing reduced form, first stage, and two-stage effects of the treatment, but weighting observations to match the HKUST population. We find that our results are essentially unchanged.

A second question is whether the July 1 protest of 2016 is a representative event within Hong Kong's anti-authoritarian movement. One might wonder whether this single, smaller than expected, event produced unusual patterns of protest participation. While we do not have experimental evidence on the effects of beliefs about others' participation on one's own from other protests, we can examine descriptive evidence on reported past protest participation available from the survey conducted in Part 1 of the study. We asked subjects about their past participation in protests associated with the anti-authoritarian movement (e.g., the Umbrella Revolution protests) and correlate past participation with beliefs regarding the political views of other subjects ${ }^{34}$ While only suggestive, we find that subjects who participated in a larger number of past protests hold more pessimistic beliefs regarding others - consistent with our experimental evidence indicating that participation in protests is not driven by a belief that there will be broad participation by others (see the Online Appendix, Figure A.2 for a graphical presentation of these findings).

A third question is, to what extent is our finding of strategic substitutes in the protest decision likely to generalize to other political movements? While we can only speculate, several characteristics of the particular setting we study may be more likely to produce a game of strategic substitutes. The Hong Kong anti-authoritarian movement is in its early stages, remains small, and is currently driven by a small core of committed participants. Such participants may be especially likely to view participation in the movement as part of their identity (Akerlof and Kranton, 2000; Benabou and Tirole. 2011), and may view participation in a smaller protest as particularly identityreinforcing when a protest is smaller. A radical core of participants may also view participation in a smaller than expected protest as being vital to maintain a movement within a dynamic game: participants may be playing a game of strategic substitutes today hoping to generate a game of strategic complements - and a mass movement — in the future.

\footnotetext{
${ }^{34}$ To be precise, we collect information on participation in the Umbrella Revolution protests; in past July 1 protests, and in "other" protests. We correlate participation in each protest with subjects' beliefs regarding others' political preferences (conditioning out subjects' own political preferences to isolate the effects of beliefs about others' preferences from one's own). Further descriptive evidence on the drivers of participation in past protests is provided in Cantoni et al. (2016).
} 


\section{Conclusion}

For hundreds of years, individuals have participated in protests demanding democratic political change from authoritarian rulers. In this, they have sometimes been successful (e.g., the Velvet Revolution, in 1989), and sometimes not (the Tiananmen Square protests in the same year). Such protests are not only events from the past: according to the human rights NGO Freedom House, $26 \%$ of the world's population - nearly two billion people - live in states classified as "not free", and the Arab Spring provides a very recent reminder that citizens of unfree states continually rise up and demand political rights ${ }^{35}$ Given the prevalence of authoritarian regimes, it is unsurprising that anti-authoritarian protest movements continue to arise, and it is important to understand their causes.

We conduct the first experiment studying individuals' strategic motives to participate in a high-stakes political protest, manipulating the beliefs of potential protest participants. We find a broad range of evidence indicating that Hong Kong students considering participating in the July 1 protest of 2016 viewed the strategic element of their decision as a game of strategic substitutes. Experimental exposure to information regarding other subjects' planned participation affects Hong Kong university students' beliefs regarding other students' actual future participation in an anti-authoritarian protest, and affects students' own protest participation. Specifically, individuals in the treatment group with prior beliefs below the truthful information provided to them updated their beliefs positively and became less likely to participate in the protest; individuals with prior beliefs above the truthful information provided to them updated their beliefs negatively, and became more likely to participate. The negative association between beliefs regarding others' participation and one's own is also seen in the naturally-occurring variation in beliefs present among control subjects in our study.

Our finding of strategic substitutes seems most plausible for small-scale protests occurring in the early stages of a political movement. That protests in the advanced stages of a political movement may look quite different - perhaps being games of strategic complements - suggests the need to study political movements as dynamic processes, rather than simply as one-shot explosive events $\sqrt{66}$ We believe that scholars of political movements and protest participation would do well to devote more attention to early-stage political movements led by a committed core of activists - these may fail; or, over time they may generate events that bring about political change and even bring down authoritarian regimes.

\footnotetext{
${ }^{35}$ Data come from Freedom House's (2016) "Freedom in the World" report, available online at https:// freedomhouse.org/sites/default/files/FH_FITW_Report_2016.pdf. last accessed August 5, 2016. By some measures, the world has become less free in recent years: Freedom House introduces its 2016 Report lamenting a "10th consecutive year of decline in global freedom." There has been an expansion of political freedom over the long run, however: Besley and Persson (2016) show that over the last two centuries, nations have become more democratic.

${ }^{36}$ See Kricheli et al. (2011) and Barbera and Jackson (2016) for models of protests as part of a dynamic game.
} 


\section{References}

Acemoglu, Daron and James A. Robinson, "Why Did the West Extend the Franchise? Democracy, Inequality, and Growth in Historical Perspective," Quarterly Journal of Economics, November 2000, 115 (4), 1167-1199.

_ and _ ,Economic Origins of Dictatorship and Democracy, Cambridge University Press, 2006.

_ and _, Why Nations Fail: the Origins of Power, Prosperity, and Poverty, New York: Crown Business, August 2012.

_ , Suresh Naidu, Pascual Restrepo, and James A. Robinson, "Democracy Does Cause Growth," December 2015. MIT working paper.

— , Tarek A. Hassan, and Ahmed Tahoun, “The Power of the Street: Evidence From Egypt's Arab Spring," NBER Working Paper, October 2014, 20665.

Aidt, Toke S. and Raphaël Franck, "How to get the snowball rolling and extend the franchise: voting on the Great Reform Act of 1832," Public Choice, January 2012, 155 (3-4), 229-250.

- and _ , "Democratization Under the Threat of Revolution: Evidence From the Great Reform Act of 1832," Econometrica, March 2015, 83 (2), 505-547.

Akerlof, George A. and Rachel E. Kranton, "Economics and Identity," Quarterly Journal of Economics, August 2000, 115 (3), 715-753.

Anderson, Michael L., "Multiple Inference and Gender Differences in the Effects of Early Intervention: A Reevaluation of the Abecedarian, Perry Preschool, and Early Training Projects," Journal of the American Statistical Association, December 2008, 103 (484), 1481-1495.

Barbera, Salvador and Matthew O Jackson, "A Model of Protests, Revolution, and Information," October 2016. Unpublished, Stanford University.

Bates, Robert H., Ghada Fayad, and Anke Hoeffler, "The State of Democracy in Sub-Saharan Africa," International Area Studies Review, December 2012, 15 (4), 323-338.

Benabou, Ronald and Jean Tirole, "Laws and Norms," November 2011. Unpublished.

Besley, Timothy and Masayuki Kudamatsu, "Health and Democracy," American Economic Review, May 2006, 96 (2), 313-318.

_ and Torsten Persson, "Democratic Values and Institutions," April 2016. LSE Working Paper.

_, Anders Jensen, and Torsten Persson, "Norms, Enforcement, and Tax Evasion," November 2014. Unpublished.

Blaydes, Lisa and Mark Andreas Kayser, "Counting Calories: Democracy and Distribution in the Developing World," International Studies Quarterly, December 2011, 55 (4), 887-908.

Cantoni, Davide, David Y. Yang, Noam Yuchtman, and Jane Zhang, "The Fundamental Determinants of Anti-Authoritarianism," November 2016. Unpublished, UC-Berkeley. 
_ , Yuyu Chen, David Y. Yang, Noam Yuchtman, and Jane Zhang, "Curriculum and Ideology," Journal of Political Economy, forthcoming.

Chwe, Michael Suk-Young, "Communication and Coordination in Social Networks," Review of Economic Studies, January 2000, 67 (1), 1-16.

Coffman, Katherine B, Lucas C Coffman, and Keith M Marzilli Ericson, "The Size of the LGBT Population and the Magnitude of Anti-Gay Sentiment are Substantially Underestimated," Management Science, forthcoming.

Coffman, Lucas, Clayton R. Featherstone, and Judd B. Kessler, "A Model of Information Nudges," November 2015. Unpublished.

de Mesquita, Ethan Bueno, "Regime Change and Revolutionary Entrepreneurs," American Political Science Review, August 2010, 104 (3), 446-466.

DellaVigna, Stefano, Ruben Enikolopov, Vera Mironova, Maria Petrova, and Ekaterina Zhuravskaya, "Cross-Border Media and Nationalism: Evidence from Serbian Radio in Croatia," American Economic Journal: Applied Economics, July 2014, 6 (3), 103-132.

Edmond, Chris, "Information Manipulation, Coordination, and Regime Change," Review of Economic Studies, October 2013, 80 (4), 1422-1458.

Enikolopov, Ruben, Alexey Makarin, and Maria Petrova, "Social Media and Protest Participation: Evidence from Russia," 2016. unpublished, Universitat Pompeu Fabra.

Fearon, James D., "Self-Enforcing Democracy," Quarterly Journal of Economics, November 2011, $126(4), 1661-1708$.

Fisman, Raymond and Yongxiang Wang, "The Distortionary Effects of Incentives in Government: Evidence from China's "Death Ceiling" Program," American Economic Journal: Applied Economics, forthcoming.

Gehlbach, Scott, Konstantin Sonin, and Milan W. Svolik, "Formal Models of Nondemocratic Politics," Annual Review of Political Science, May 2016, 19, 565-584.

Gerber, Alan, Mitchell Hoffman, John Morgan, and Collin Raymond, “One in a Million: Field Experiments on Perceived Closeness of the Election and Voter Turnout;," January 2017. Unpublished, University of Toronto.

Gerber, Alan S., Gregory A. Huber, David Doherty, Conor M. Dowling, Connor Raso, and Shang E. Ha, "Personality Traits and Participation in Political Processes," Journal of Politics, July 2011, 73 (3), 692-706.

Gerring, John, Philip Bond, William Barndt, and Carola Moreno, "Democracy and Growth: A Historical Perspective," World Politics, April 2005, 57 (3), 323-364.

González, Felipe, "Collective Action in Networks: Evidence from the Chilean Student Movement," October 2016. Unpublished, UC-Berkeley.

Granovetter, Mark, "Threshold Models of Collective Behavior," American Journal of Sociology, May 1978, 83, 489-515. 
Jia, Ruixue, "Pollution for Promotion," April 2014. Unpublished, UC-San Diego.

- and Torsten Persson, "Individual vs. Social Motives in Identity Choice: Theory and Evidence from China," April 2016. Unpublished, UC-San Diego.

King, Gary, Jennifer Pan, and Margaret E. Roberts, "How Censorship in China Allows Government Criticism but Silences Collective Expression," American Political Science Review, May 2013, 107 (2), 326-343.

Kricheli, Ruth, Yair Livne, and Beatriz Magaloni, "Taking to the Streets: Theory and Evidence on Protests under Authoritarianism," APSA Annual Meeting Paper, April 2011.

Kung, James Kai-Sing and Shuo Chen, "The Tragedy of the Nomenklatura: Career Incentives and Political Radicalism during China's Great Leap Famine," American Political Science Review, February 2011, 105 (01), 27-45.

Kuran, Timur, "Sparks and Prairie Fires: A Theory of Unanticipated Political Revolution," Public choice, April 1989, 61 (1), 41-74.

_ , “The East European Revolution of 1989: Is it Surprising that We Were Surprised?," American Economic Review, May 1991, 81 (2), 121-125.

_ , Private Truths, Public Lies: The Social Consequences of Preference Falsification, Cambridge, Mass.: Harvard University Press, 1997.

Lizzeri, Alessandro and Nicola Persico, "Why did the Elites Extend the Suffrage? Democracy and the Scope of Government, with an Application to Britain's "Age of Reform"," Quarterly Journal of Economics, May 2004, 119 (2), 707-765.

Llavador, Humberto and Robert J. Oxoby, "Partisan Competition, Growth, and the Franchise," Quarterly Journal of Economics, August 2005, 120 (3), 1155-1189.

Lohmann, Susanne, "The Dynamics of Informational Cascades: The Monday Demonstrations in Leipzig, East Germany, 1989-91," World Politics, October 1994, 47 (1), 42-101.

Lorentzen, Peter, "Regularizing Rioting: Permitting Public Protest in an Authoritarian Regime," Quarterly Journal of Political Science, April 2013, 8 (2), 127-158.

Madestam, Andreas, Daniel Shoag, Stan Veuger, and David Yanagizawa-Drott, "Do Political Protests Matter? Evidence from the Tea Party Movement," Quarterly Journal of Economics, October 2013, 128 (4), 1633-1685.

Martinez-Bravo, Monica, Gerard Padró i Miquel, Nancy Qian, and Yang Yao, "Political Reform in China: The Effect of Local Elections," NBER Working Paper, July 2014, 18101.

Meyersson, Erik, "Political Man on Horseback: Military Coups and Development," April 2016. Unpublished, SITE, Stockholm School of Economics.

Olson, Mancur, The Logic of Collective Action: Public Goods and the Theory of Groups, New York, NY: Schocken Books, 1965. 
Opp, Karl-Dieter and Christiane Gern, "Dissident Groups, Personal Networks, and Spontaneous Cooperation: The East German Revolution of 1989," American Sociological Review, October 1993, 58 (5), 659-680.

Papaioannou, Elias and Gregorios Siourounis, "Democratisation and Growth," Economic Journal, October 2008, 118 (532), 1520-1551.

Persson, Torsten and Guido Tabellini, "Democracy and Development: The Devil in the Details," American Economic Review, May 2006, 96 (2), 319-324.

_ and _ ,"The Growth Effects of Democracy: Is it Heterogenous and How Can It Be Estimated?," in Elhanan Helpman, ed., Institutions and Economic Performance, Cambridge, Mass.: Harvard University Press, 2008.

Przeworski, Adam and Fernando Limongi, "Political Regimes and Economic Growth," Journal of Economic Perspectives, Summer 1993, 7 (3), 51-69.

_, Michael E. Alvarez, José Antonio Cheibub, and Fernando Limongi, Democracy and Development: Political Institutions and Well-Being in the World, 1950-1990, Cambridge and New York: Cambridge University Press, 2000.

Raghavarao, Damaraju and Walter T. Federer, "Block Total Response as an Alternative to the Randomized Response Method in Surveys," Journal of the Royal Statistical Society, Series B, 1979, $41(1), 40-45$.

Reny, Marie-Eve, "Authoritarianism as a Research Constraint: Political Scientists in China," Social Science Quarterly, December 2016, 97 (4), 909-922.

Rodrik, Dani and Romain Wacziarg, "Do Democratic Transitions Produce Bad Economic Outcomes?," American Economic Review, May 2005, 95 (2), 50-55.

Yanagizawa-Drott, David, "Propaganda and Conflict: Evidence from the Rwandan Genocide," Quarterly Journal of Economics, December 2014, 129 (4), 1947-1994. 
Figures and tables

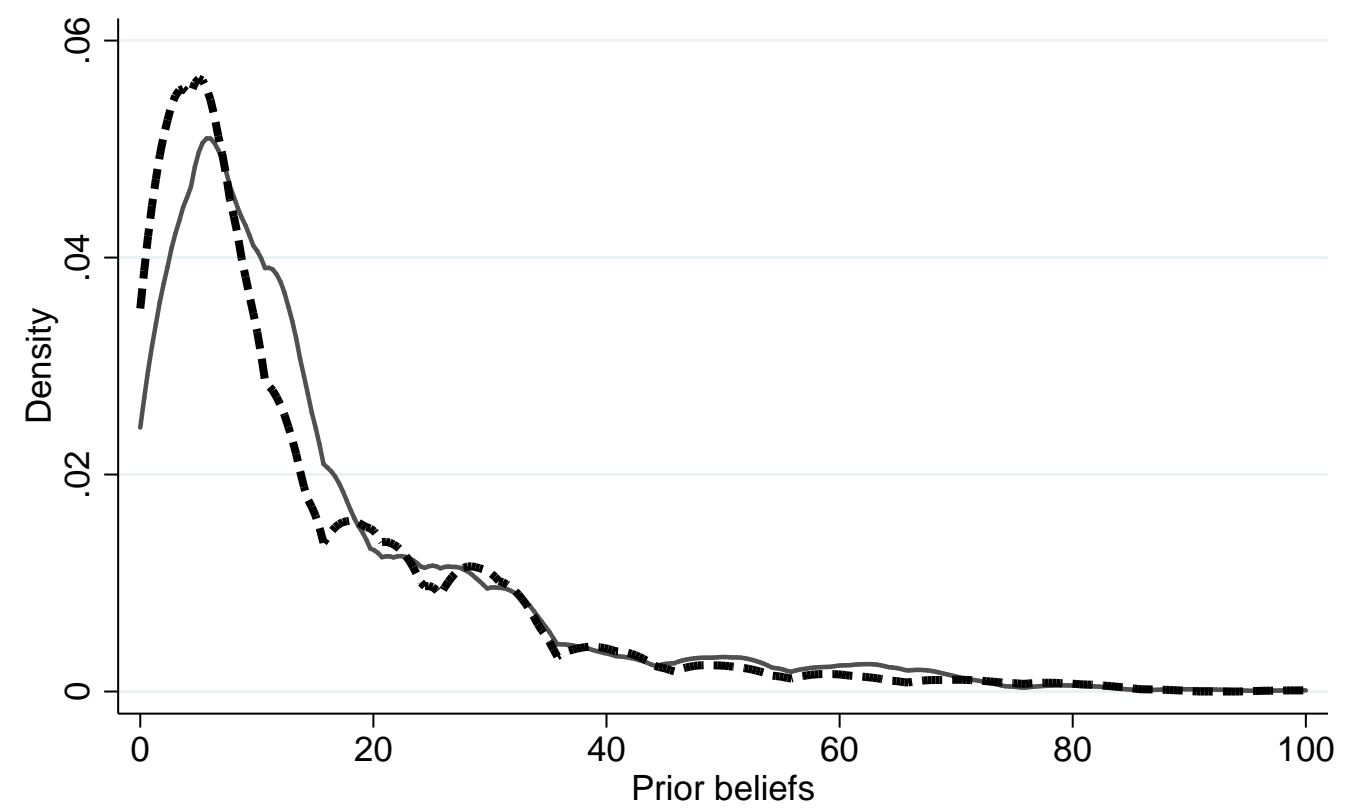

Re: planned participation

- - - - Re: actual participation (among HKUST)

Figure 1: Distribution of prior beliefs regarding the planned protest participation and actual protest participation of HKUST survey participants. 


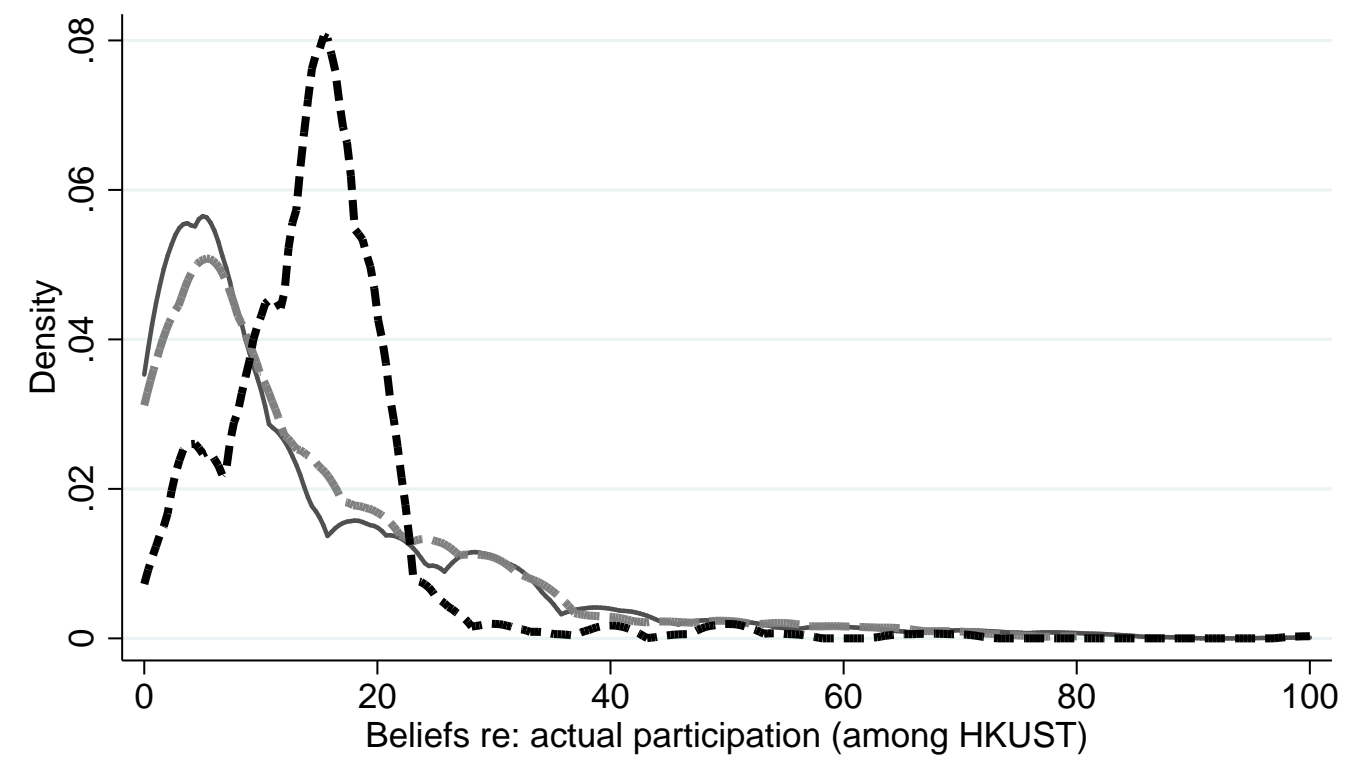

Prior to follow-up
- Posterior to follow-up (control group)
_ - Posterior to follow-up (treatment group)

Figure 2: Distribution of prior beliefs and posterior beliefs regarding the actual protest participation of HKUST survey participants. 

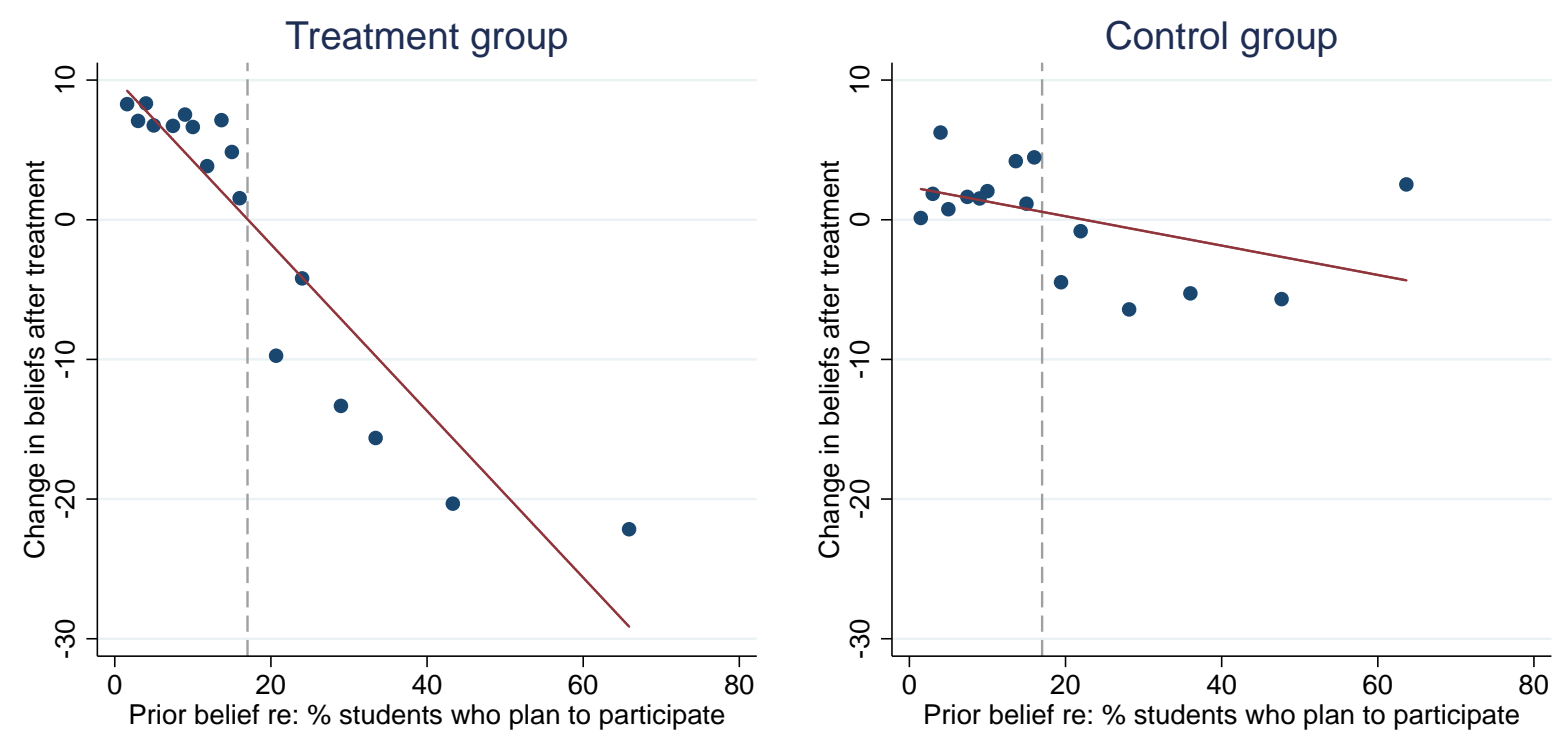

Figure 3: Changes in beliefs (posteriors minus priors) regarding the actual protest participation of HKUST survey participants, presented separately by subjects' treatment status. 


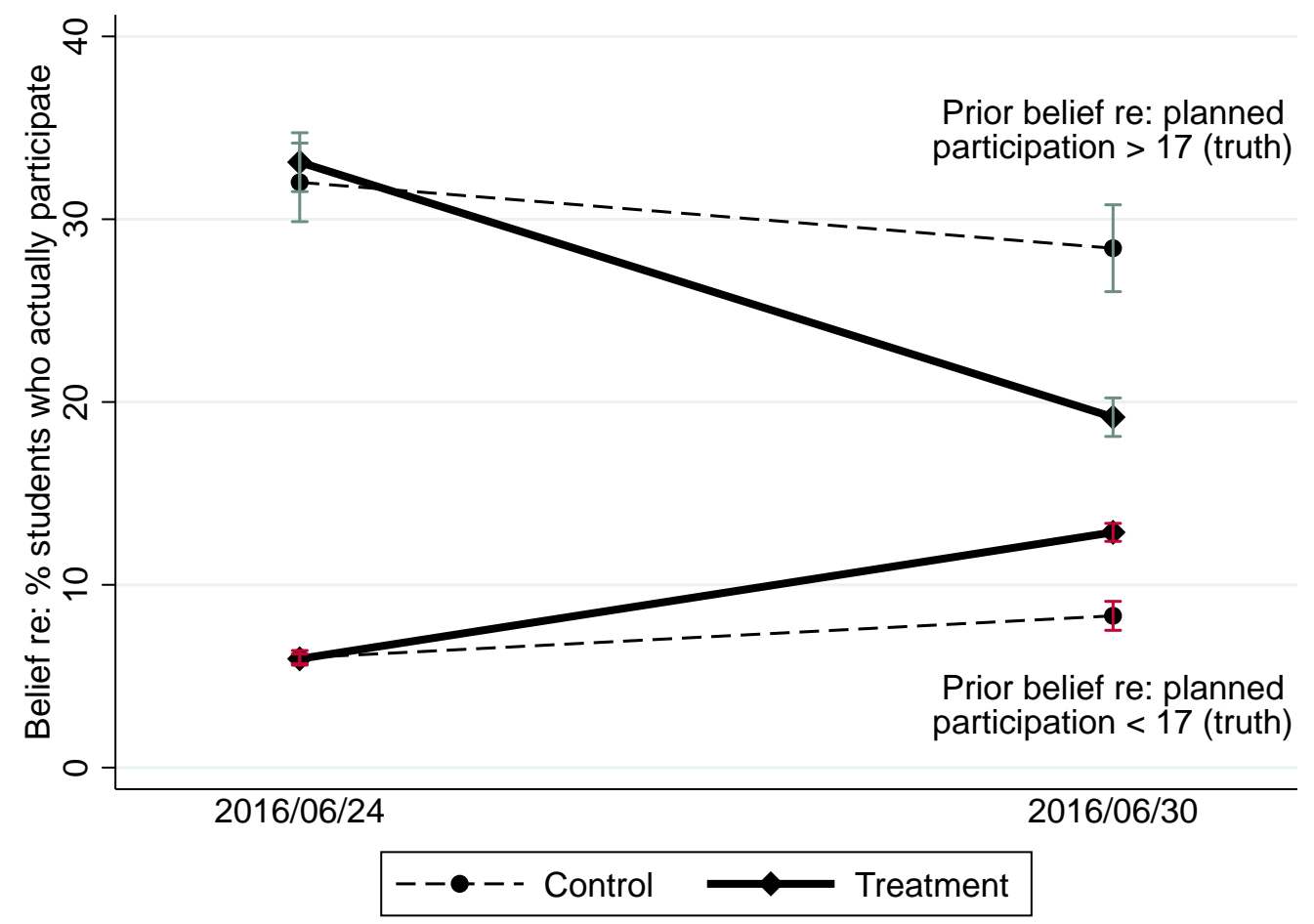

Figure 4: Treatment effect on beliefs ("first stage"). Graph shows prior and posterior beliefs regarding the actual protest participation of HKUST survey participants, split according to subjects' treatment status and according to prior beliefs. Subsamples of subjects are divided according to whether beliefs regarding the planned protest participation of HKUST survey participants were above or below the true level of $17 \%$. 


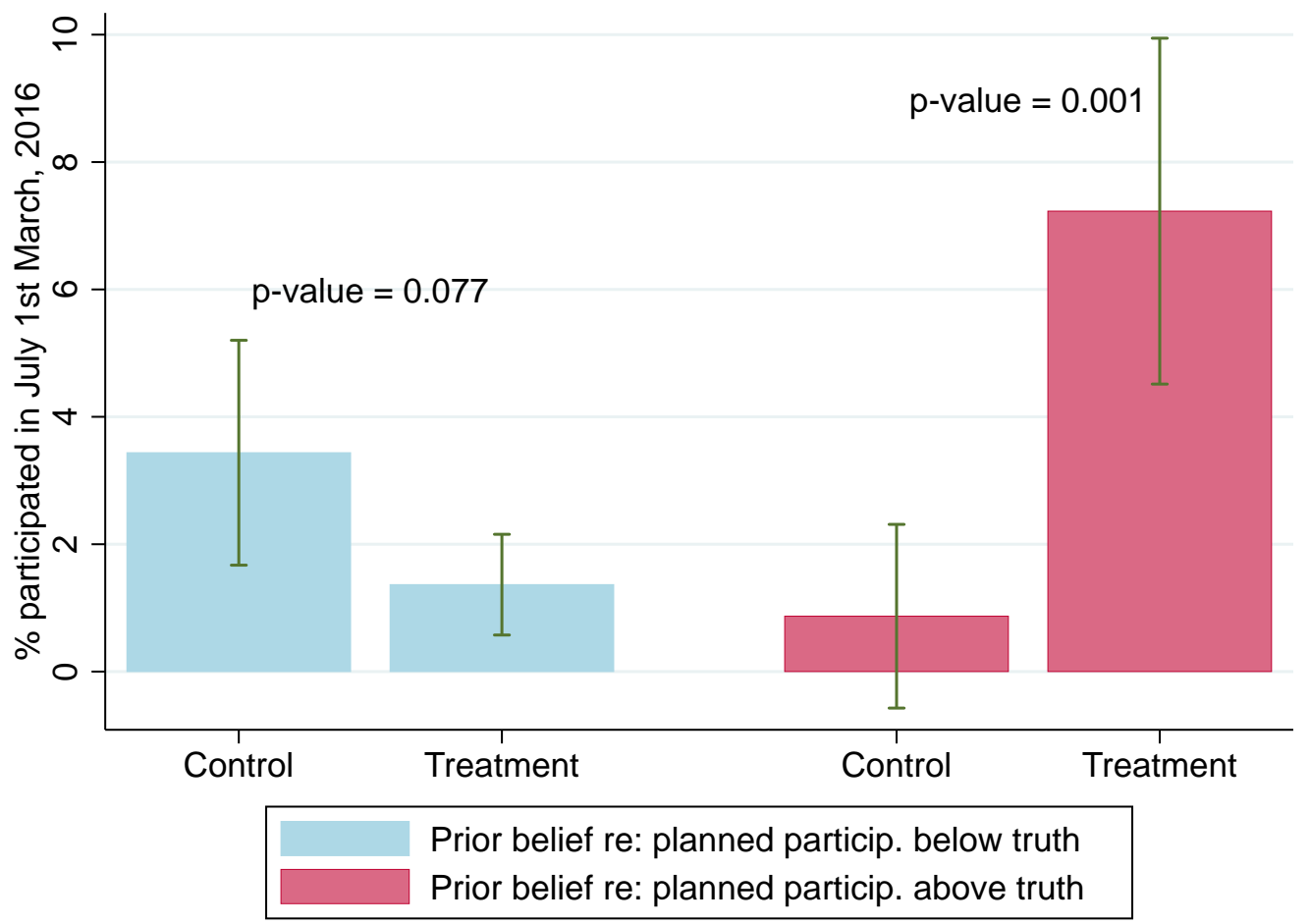

Figure 5: Treatment effect on protest participation ("reduced form"). Graph shows self-reported participation in the July 1 protest of 2016, split according to subjects' treatment status and according to prior beliefs. Subsamples of subjects are divided according to whether beliefs regarding the planned protest participation of HKUST survey participants were above or below the true level of $17 \%$. 


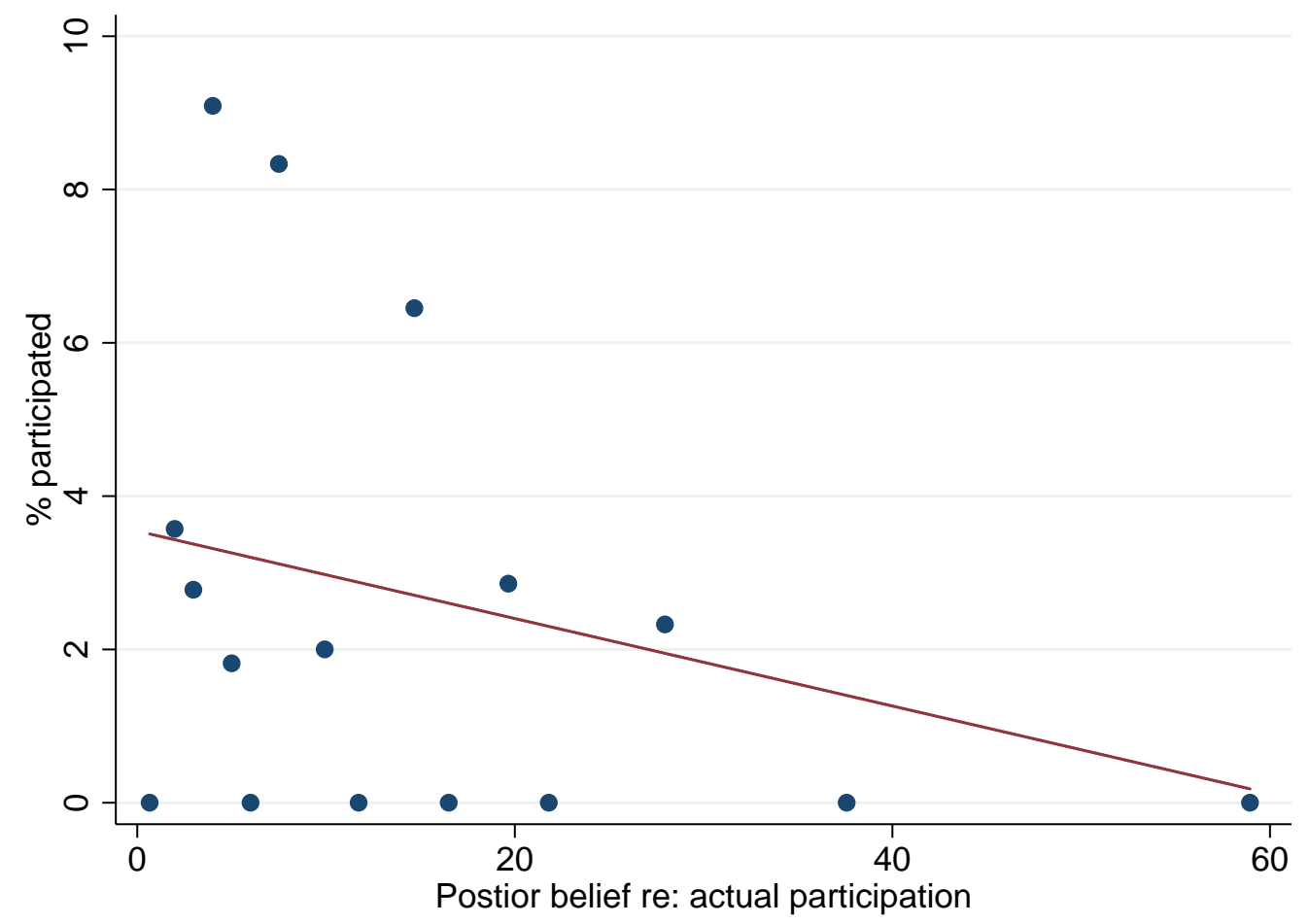

Figure 6: Binned scatter plot showing the percentage of subjects in the control group who participated in the protest against subjects' posterior beliefs regarding the actual protest participation of HKUST survey participants. 


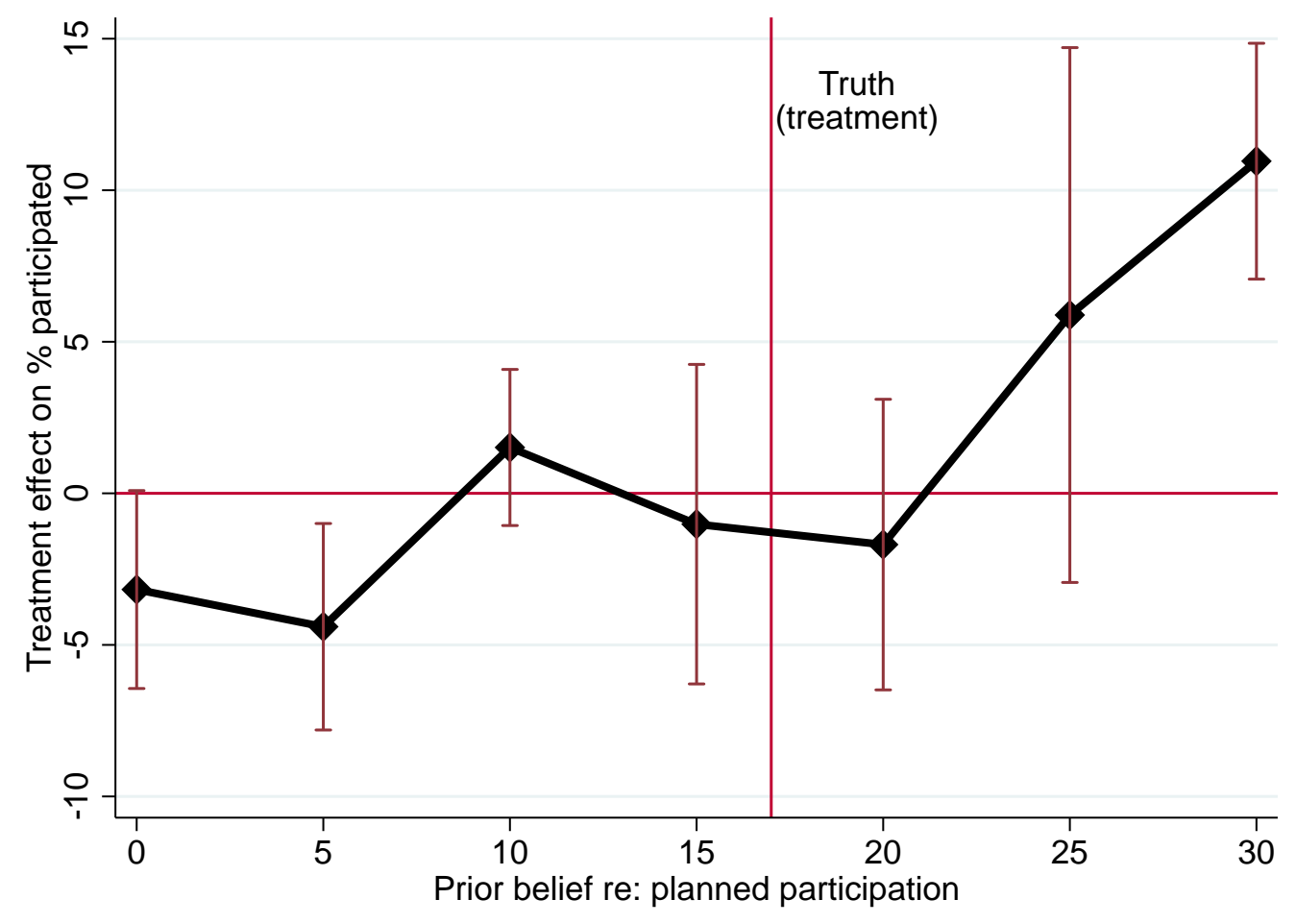

Figure 7: Treatment effect on protest participation ("reduced form"), disaggregated by prior beliefs regarding the planned participation of HKUST survey participants (bins are 5 percentage points wide). 


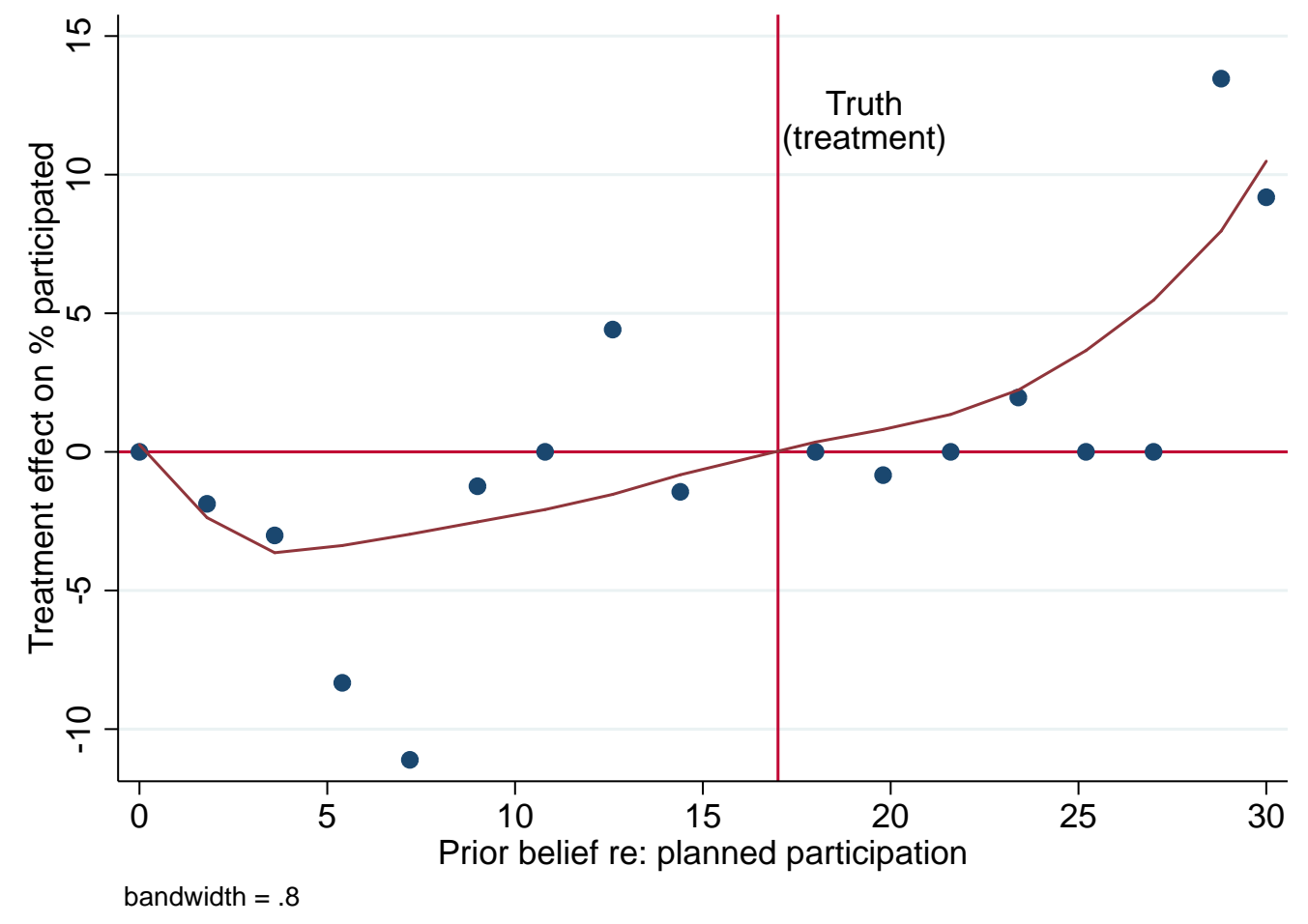

Figure 8: Non-parametric treatment effect on protest participation ("reduced form"), across prior beliefs regarding the planned participation of HKUST survey participants, smoothed using a lowess kernel at bandwidth $=0.8$. 


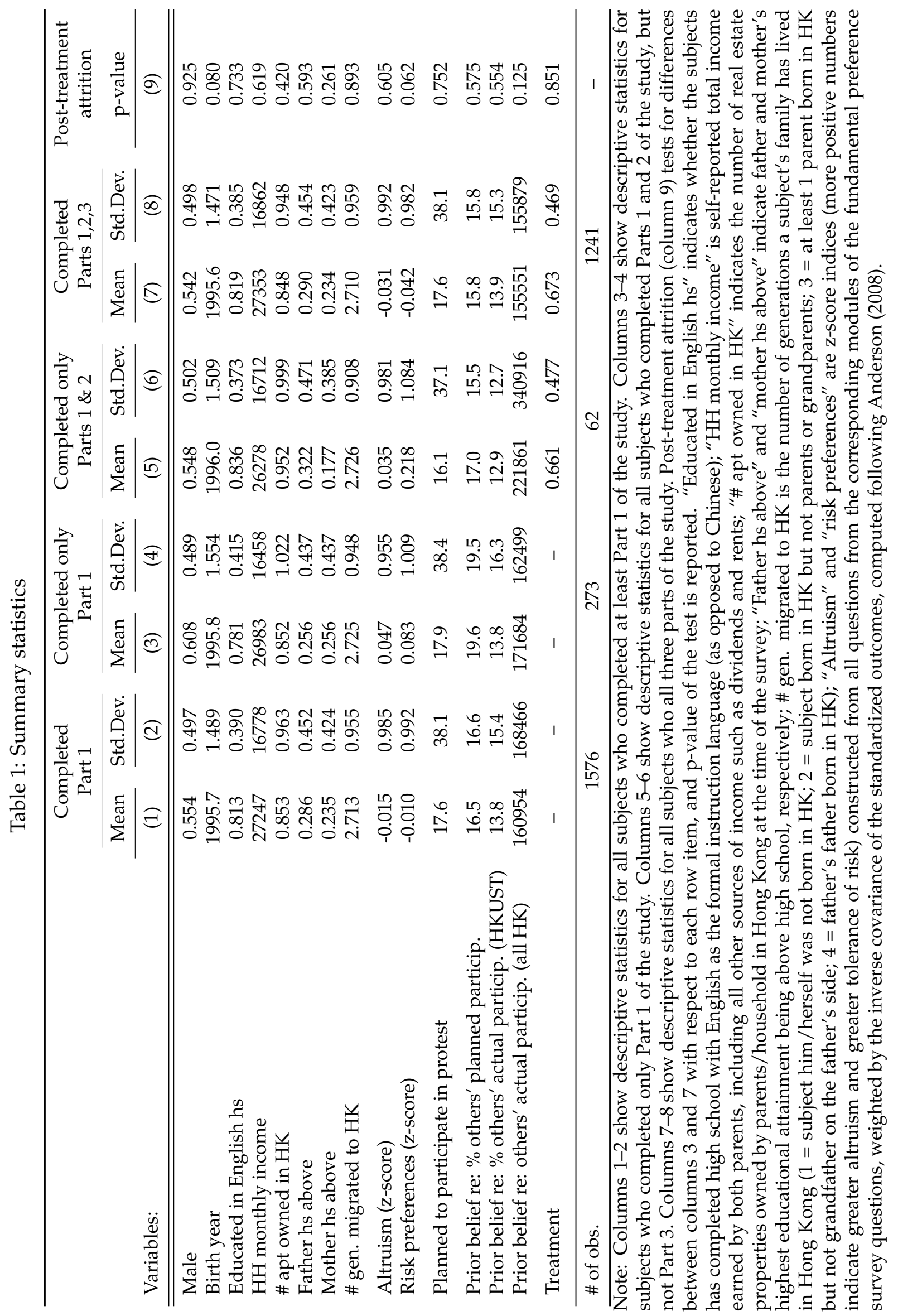




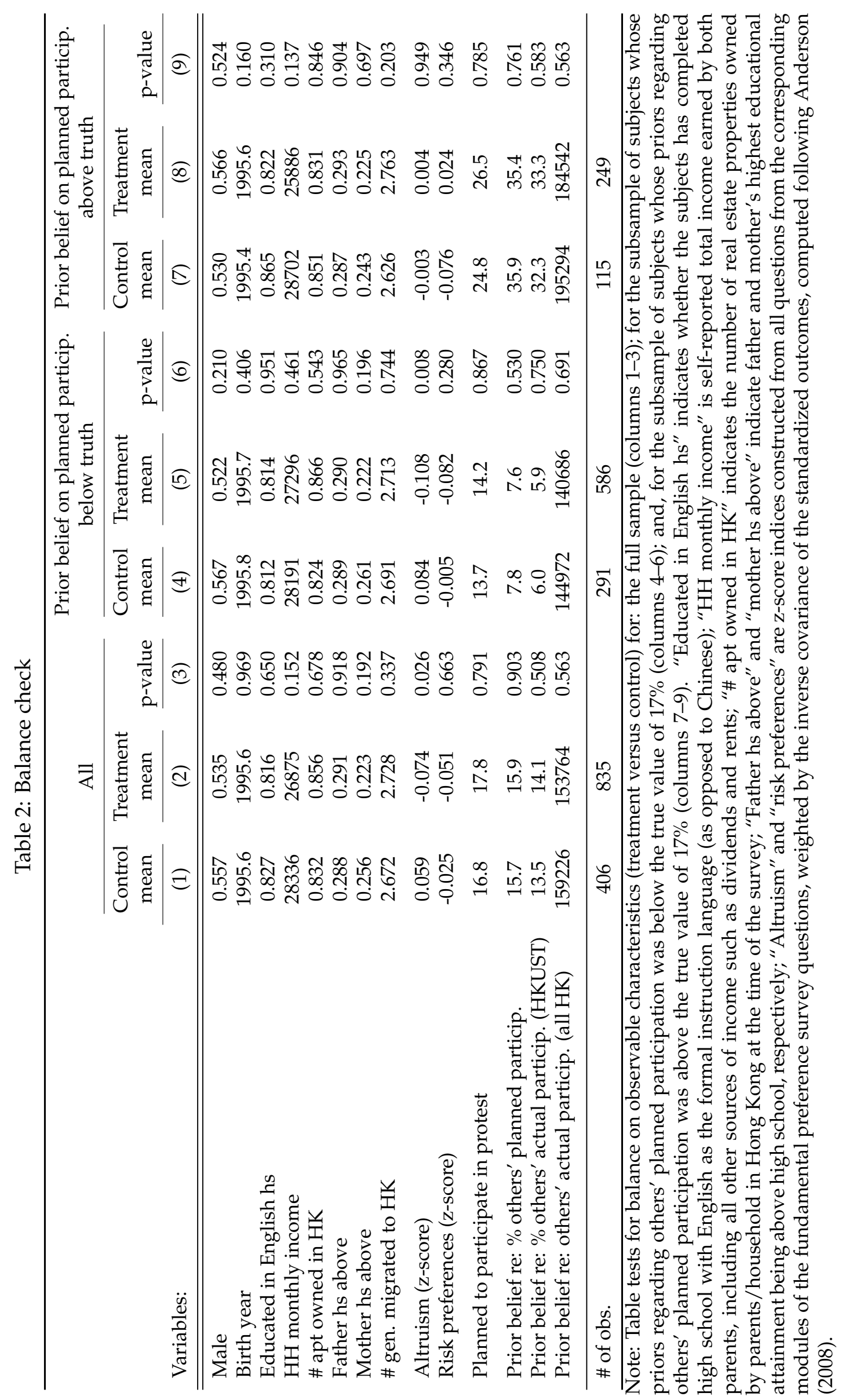


Table 3: Item count experiments: willingness to respond to direct questions

\begin{tabular}{lcc}
\hline Attitudes: & $\begin{array}{c}\text { "Yes" in } \\
\text { direct question }\end{array}$ & $\begin{array}{c}\Delta \text { when } \\
\text { veil is provided }\end{array}$ \\
\hline \hline Unfavorable view of CCP & 0.923 & 0.020 \\
& & {$[0.059]$} \\
Consider self as Hong Kongese & 0.879 & -0.063 \\
& & {$[0.051]$} \\
Support for HK independence & 0.465 & 0.054 \\
& & {$[0.057]$} \\
Support violence in pursuit of HK's political rights & 0.217 & $0.169^{* * *}$ \\
& & {$[0.050]$}
\end{tabular}

Note: The left hand column presents the fraction of 790 Hong Kong local students who expressed the corresponding attitude in response to a direct question. The right hand column presents the difference between that fraction and the fraction estimated to support the attitude using an item count technique ("list experiment"). The 790 students asked the direct questions also represent the control group for the list experiment; the remaining 786 Hong Kong local students represent the treatment group. Assignment to "direct question" and "list experiment" conditions was random. This table also appears in Cantoni et al. (2016). 
Table 4: Treatment effect on posterior beliefs

\begin{tabular}{|c|c|c|c|c|c|c|}
\hline \multirow{3}{*}{ Sample: } & \multicolumn{3}{|c|}{$\begin{array}{l}\text { Change in beliefs on \% participation } \\
\text { among HKUST students }\end{array}$} & \multicolumn{3}{|c|}{$\begin{array}{c}\text { Change in belief on total \# participation } \\
\text { among HK population }\end{array}$} \\
\hline & $\begin{array}{l}\text { Prior below } \\
\text { truth }\end{array}$ & $\begin{array}{l}\text { Prior above } \\
\text { truth }\end{array}$ & All subjects & $\begin{array}{l}\text { Prior below } \\
\text { truth }\end{array}$ & $\begin{array}{l}\text { Prior above } \\
\text { truth }\end{array}$ & All subjects \\
\hline & $(1)$ & $(2)$ & (3) & (4) & (5) & (6) \\
\hline \multicolumn{7}{|l|}{ Panel A: without controls } \\
\hline Treatment & $\begin{array}{l}4.496^{* * *} \\
{[0.552]}\end{array}$ & $\begin{array}{c}-10.187^{* * *} \\
{[1.611]}\end{array}$ & & $\begin{array}{l}14644.7 \\
{[7195.7]}\end{array}$ & $\begin{array}{c}-5120.5 \\
{[15009.1]}\end{array}$ & \\
\hline $\begin{array}{l}\text { Treatment } \\
\text { (direction adj.) }\end{array}$ & & & $\begin{array}{l}9.831^{* * *} \\
{[0.491]}\end{array}$ & & & $\begin{array}{c}11337.7^{* * *} \\
{[3656.6]}\end{array}$ \\
\hline \multicolumn{7}{|c|}{ Panel B: controls for demographic characteristics and prior beliefs } \\
\hline Treatment & $\begin{array}{l}4.699^{* * * *} \\
{[0.544]}\end{array}$ & $\begin{array}{c}-11.687^{* * * *} \\
{[1.629]}\end{array}$ & & $\begin{array}{l}16991.1 \\
{[7200.0]}\end{array}$ & $\begin{array}{c}-9360.7 \\
{[25788.4]}\end{array}$ & \\
\hline $\begin{array}{l}\text { Treatment } \\
\text { (direction adj.) }\end{array}$ & & & $\begin{array}{c}6.945^{* * * *} \\
{[0.542]}\end{array}$ & & & $\begin{array}{l}9303.0^{* *} \\
{[4769.7]}\end{array}$ \\
\hline Observations & 873 & 361 & 1234 & 873 & 361 & 1234 \\
\hline DV mean (control grp.) & 2.417 & -3.805 & 0.664 & -17912.3 & -19518.5 & -18364.9 \\
\hline DV std. dev. (control grp.) & 7.744 & 13.01 & 9.914 & 102207 & 144307 & 115441 \\
\hline DV mean (all) & 5.430 & -10.80 & 0.681 & -8098.8 & -23036.2 & -12468.7 \\
\hline DV std. dev. (all) & 7.874 & 16.19 & 13.23 & 97847 & 116412 & 103798 \\
\hline
\end{tabular}

Note: Table shows first stage effects: the effects of the experimental treatment on subjects' changes in beliefs regarding others' actual protest participation (posteriors minus priors). Columns 1-3 show effects on posterior beliefs regarding other experimental subjects' actual participation, while columns 4-6 show effects on posterior beliefs regarding the total turnout at the protest by all Hong Kong citizens. Columns 1 and 4 (2 and 5) show effects on posterior beliefs for the subsample of subjects whose priors regarding others' planned participation were below (above) the true value of $17 \%$. In columns 3 and 6 , all subjects are pooled and treatment is coded as " -1 " for subjects whose priors regarding others' planned participation was above $17 \%$. Panel A is estimated without any controls; Panel B replicates the analysis in Panel A, but adds controls for subjects' demographic characteristics and for the levels of subjects' prior beliefs. 
Table 5: Treatment effect on protest participation

\begin{tabular}{|c|c|c|c|c|}
\hline \multirow{3}{*}{ Sample: } & \multicolumn{4}{|c|}{ Participated in 2016 July 1st March } \\
\hline & \multicolumn{2}{|c|}{$\begin{array}{l}\text { Prior belief re: planned } \\
\text { particip. below truth }\end{array}$} & \multicolumn{2}{|c|}{$\begin{array}{l}\text { Prior belief re: planned } \\
\text { particip. above truth }\end{array}$} \\
\hline & (1) & (2) & (3) & (4) \\
\hline \multicolumn{5}{|l|}{ Panel A: two-stage least squares } \\
\hline Change in belief & $\begin{array}{c}-0.468^{* *} \\
{[0.234]}\end{array}$ & $\begin{array}{l}-0.422^{*} \\
{[0.228]}\end{array}$ & $\begin{array}{c}-0.626^{* * *} \\
{[0.248]}\end{array}$ & $\begin{array}{c}-0.591^{* * *} \\
{[0.219]}\end{array}$ \\
\hline \multicolumn{5}{|l|}{ Panel B: 1st stage on changes in belief } \\
\hline Treatment & $\begin{array}{l}4.496^{* * *} \\
{[0.546]}\end{array}$ & $\begin{array}{l}4.699^{* * *} \\
{[0.554]}\end{array}$ & $\begin{array}{c}-10.19^{* * *} \\
{[1.760]}\end{array}$ & $\begin{array}{l}-11.69^{* * *} \\
{[1.762]}\end{array}$ \\
\hline Adj. $R^{2}$ & 0.071 & 0.073 & 0.083 & 0.160 \\
\hline \multicolumn{5}{|l|}{ Panel C: reduced form } \\
\hline Treatment & $\begin{array}{l}-2.071^{*} \\
[1.172]]\end{array}$ & $\begin{array}{l}-1.959^{*} \\
{[1.219]}\end{array}$ & $\begin{array}{c}6.359^{* * *} \\
{[1.860]}\end{array}$ & $\begin{array}{c}6.851^{* * *} \\
{[2.036]}\end{array}$ \\
\hline $\begin{array}{l}\text { Observations } \\
\text { Control for demographics } \\
\text { Control for prior beliefs }\end{array}$ & $\begin{array}{l}877 \\
\text { No } \\
\text { No }\end{array}$ & $\begin{array}{l}857 \\
\text { Yes } \\
\text { Yes }\end{array}$ & $\begin{array}{l}364 \\
\text { No } \\
\text { No }\end{array}$ & $\begin{array}{l}349 \\
\text { Yes } \\
\text { Yes }\end{array}$ \\
\hline $\begin{array}{l}\text { 1st stage DV mean (control grp.) } \\
\text { 1st stage DV mean (control grp.) } \\
\text { 1st stage DV mean (all) } \\
\text { 1st stage DV mean (all) }\end{array}$ & $\begin{array}{l}2.417 \\
7.744 \\
5.430 \\
7.874\end{array}$ & $\begin{array}{l}2.417 \\
7.744 \\
5.430 \\
7.874\end{array}$ & $\begin{array}{c}-3.805 \\
13.01 \\
-10.80 \\
16.19\end{array}$ & $\begin{array}{c}-3.805 \\
13.01 \\
-10.80 \\
16.19\end{array}$ \\
\hline $\begin{array}{l}\text { 2nd stage DV mean (control grp.) } \\
\text { 2nd stage DV std. dev. (control grp.) } \\
\text { 2nd stage DV mean (all) } \\
\text { 2nd stage DV std. dev. (all) }\end{array}$ & $\begin{array}{l}3.436 \\
18.25 \\
2.052 \\
14.19\end{array}$ & $\begin{array}{l}3.436 \\
18.25 \\
2.052 \\
14.19\end{array}$ & $\begin{array}{c}0.870 \\
9.33 \\
5.220 \\
22.27\end{array}$ & $\begin{array}{c}0.870 \\
9.33 \\
5.220 \\
22.27\end{array}$ \\
\hline
\end{tabular}

Note: Table shows reduced form estimates (Panel C); first stage estimates (Panel B); and, two-stage estimates (Panel A). The reduced form estimates the effects of the experimental treatment on subjects' own protest participation. The first stage estimates the effects of the experimental treatment on subjects' changes in beliefs regarding other subjects' actual protest participation (posteriors minus priors). The two-stage estimates exploit variation in beliefs regarding other subjects' participation induced by the experimental treatment to estimate the effect of beliefs about others' protest turnout on one's own turnout. Columns 1-2 (3-4) show effects on posterior beliefs regarding other experimental subjects' actual participation and on one's own protest turnout for the subsample of subjects whose priors regarding others' planned participation were below (above) the true value of $17 \%$. Columns 1 and 3 are estimated without any controls; columns 2 and 4 add controls for subjects' demographic characteristics and for the levels of subjects' prior beliefs. 


\section{ONLINE APPENDIX, NOT FOR PUBLICATION}

A.1 


\section{Appendix A Experimental design transcript}

\section{A.1 Pre-protest module (Part 2)}

\section{Version A: Control Group}

[Screen 1]

Welcome screen: thank you for participating in this follow-up survey.

[Screen 2]

Remember that we offered you:

1. A HKD 10 bonus payment for accurately guessing the percentage of HKUST survey participants who would actually attend this July 1 March (七一遊行);

2. An additional HKD 10 bonus payment for accurately guessing the total number of Hong Kong citizens would actually attend this July 1 March (七一遊行)

In last week's survey, you guessed that:

1. [embedded individual value] \% of HKUST survey participants would attend this July 1 March;

2. A total of [embedded individual value] Hong Kong citizens would attend this July 1 March.

Perhaps since then your views have changed.

We now ask you again to provide guesses about actual attendance of the July 1 March.

Instead of your guesses in the previous survey, we will use today's guesses to determine your bonus payment.

1. How many people in total do you think will participate in the July $1^{\text {st }}$ March (七一大遊行) in 2016?

- If your guess is within $10 \%$ of what will be reported by the HKUPOP (香港大學民意研究計劃) after the July $1^{\text {st }}$ March in 2016, then you will earn a bonus payment of $\underline{\text { HKD } 10 .}$

- To give you a sense, according to HKUPOP's report, among the July $1^{\text {st }}$ March that took place between 2003 and 2015:

- The lowest attendance in a given year is: 17,000 (in 2008);

○ The highest attendance in a given year is: 462,000 (in 2003).

[Slider bar, ranging from 0 to 1,000,000]

2. Please guess what percentage of the participants from HKUST of this study will participate in the July $1^{\text {st }}$ March (七一大遊行) in 2016?

- If your guess is within 2 percentage points of the percent of students who actually participate, you will earn a bonus payment of $\underline{\text { HKD } 10}$.

$\%$

[Fill in the number: between 0-100] 
[Screen 3]

You have now finished the follow-up survey module.

Thank you very much for your participation. We will inform you about the total payment you have earned from last week and today's surveys - the payment will be deposited to your bank account via the HKUST Student Information System (SIS).

We will also inform you about future study opportunities, and we look forward to seeing you again soon!

Feel free to contact us at jzproject@ust.hk if you have questions and/or concerns regarding this study.

\section{Version B: Treatment Group}

[Screen 1]

Welcome screen: thank you for participating in this follow-up survey.

[Screen 2]

In this follow-up survey, we wish to update you on your fellow HKUST survey participants' planned participation in this year's July 1 March (七一遊行).

Recall that you guessed that [embedded individual value] \% of HKUST survey participants would plan to attend the July 1 March.

Based on last week's survey, the true percentage of survey participants who plan to attend the July 1 March is $17 \%$.

Remember that we offered you:

1. A HKD 10 bonus payment for accurately guessing the percentage of HKUST survey participants who would actually attend this July 1 March (七一遊行);

2. An additional HKD 10 bonus payment for accurately guessing the total number of Hong Kong citizens would actually attend this July 1 March (七一遊行).

In last week's survey, you guessed that:

1. [embedded individual value] $\%$ of HKUST survey participants would attend this July 1 March;

2. A total of [embedded individual value] Hong Kong citizens would attend this July 1 March.

Perhaps since then your views have changed.

We now ask you again to provide guesses about actual attendance of the July 1 March. 
1. How many people in total do you think will participate in the July $1^{\text {st }}$ March (七一大遊行) in 2016?

- If your guess is within $10 \%$ of what will be reported by the HKUPOP(香港大學民意研究計劃) after the July $1^{\text {st }}$ March in 2016, then you will earn a bonus payment of HKD 10.

- To give you a sense, according to HKUPOP's report, among the July $1^{\text {st }}$ March that took place between 2003 and 2015:

- The lowest attendance in a given year is: 17,000 (in 2008);

○ The highest attendance in a given year is: 462,000 (in 2003).

[Slider bar, ranging from 0 to 1,000,000]

2. Please guess what percentage of the participants from HKUST of this study will participate in the July $1^{\text {st }}$ March (七一大遊行) in 2016?

- If your guess is within 2 percentage points of the percent of students who actually participate, you will earn a bonus payment of $\underline{\mathrm{HKD} 10}$.

$\%$

[Fill in the number: between 0-100]

[Screen 3]

You have now finished the follow-up survey module.

Thank you very much for your participation. We will inform you about the total payment you have earned from last week and today's surveys - the payment will be deposited to your bank account via the HKUST Student Information System (SIS).

We will also inform you about future study opportunities, and we look forward to seeing you again soon!

Feel free to contact us at jzproject@ust.hk if you have questions and/or concerns regarding this study. 


\section{A.2 Post-protest module (Part 3)}

[Screen 1]

Welcome screen: thank you for participating in this follow-up survey.

[Screen 2]

1. Did you attend the July 12016 March?

$\{$ IF "NO”, skip to Q3. $\}$

2. Which political group's crowd did you join during the March? (please choose all that apply)

公民黨 Givic Party

民主黨 Democratic Party

人民力量 People Power

工黨 Labour Party

社民連 League of Social Democrats

街工 Neighbourhood and Worker Service Centre

新民主同盟 Neo Democrats

青年新政 Youngspiration

香港眾志 Demosisto

熱血公民 Givic Passion

本土民主前線 Hong Kong Indigenous

科大學生會 HKUST Student Union

科大行動 ProgressUST

學聯 HKFS

普羅政治學院 Proletariat Political Institute

香港花生 HKpeanut

D100 民間電台 D100 Radio

職工盟 Hong Kong Confederation of Trade Unions

雷動計劃 ThunderGo

小麗民主教室 Siu Lai Democracy Groundwork

土地正義聯盟 Land Justice League

法輪功 Falun Gong

大陸朱 Chu Siu-hung

爭取全民退休保障聯席 Alliance for Universal Pension 懇請政府重訂屋宇飼養犬隻條例聯盟 Give Dogs a Home 旺角鳩鳴團 Mong Kok Shopping Revolution 
良心之友 Friends of Conscience

撐傘落區 Umbrella Blossom

其他 Others

3. What was your general impression of the March (300 words or less)?

$\{$ Open-ended\}

4. Recall that in the previous survey rounds, we asked about your friends at HKUST. To the best of your knowledge, how many of the friends you named (listed below) attended?

\{Multiple round\}

[Screen 3]

So far, you have earned: HKD \{inserted individual payment value $\}$ in total from participating in our study.

The payment will be deposited directly to your bank account via the HKUST Student Information System (SIS), in approximately 5-8 weeks.

Feel free to contact us at jzproject@ust.hk if you have questions and/or concerns regarding this study. 


\section{Appendix B Appendix figures and tables}
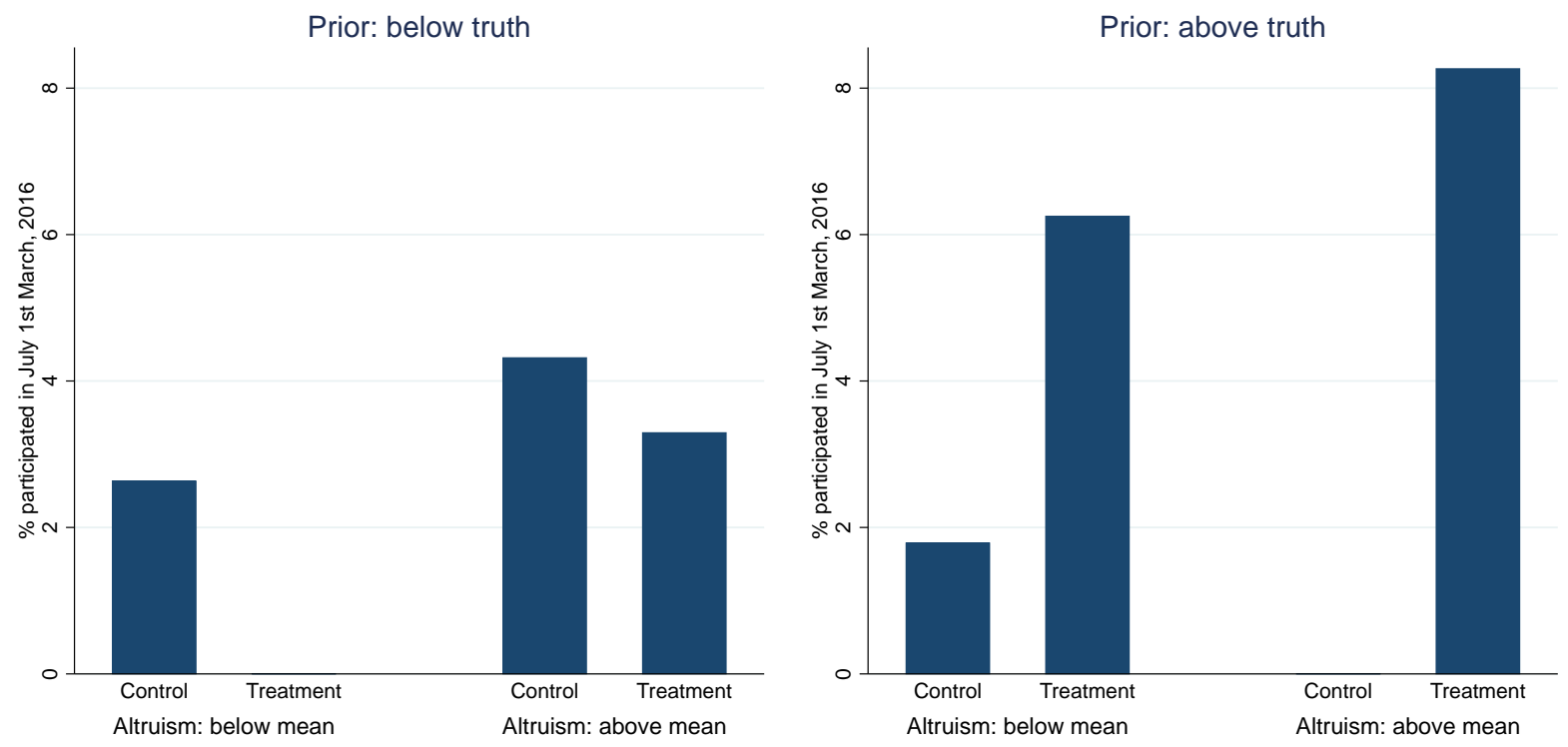

Figure A.1: Heterogeneous treatment effect on protest participation ("reduced form"), split by whether altruism (a z-score index constructed using questions from Part 1 of the study) is above or below the mean level. 

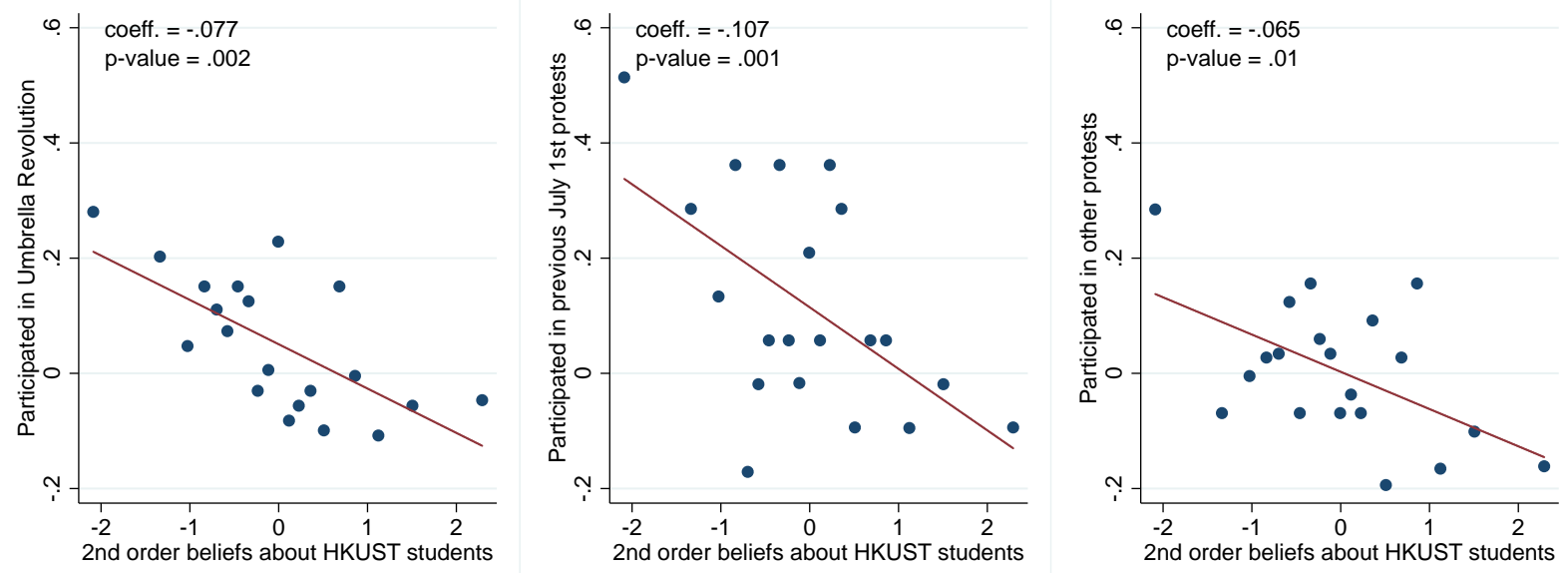

Figure A.2: Binned scatter plots predicting protest participation (standardized) using beliefs about other HKUST students (z-score indices constructed using questions from Part 1 of the study)/ Beliefs about other subjects are residuals, conditional on one's own reported attitudes on the relevant dimension. 
Table A.1: Sample representativeness

\begin{tabular}{|c|c|c|c|}
\hline & \multirow{2}{*}{$\frac{\text { Population ratio }}{(1)}$} & \multirow{2}{*}{$\frac{\text { Sample ratio }}{(2)}$} & \multirow{2}{*}{$\frac{\text { T-test } p \text {-value }}{(3)}$} \\
\hline & & & \\
\hline Male & 0.615 & 0.543 & 0.000 \\
\hline Entering cohort of 2012 & 0.240 & 0.225 & 0.172 \\
\hline Entering cohort of 2013 & 0.254 & 0.228 & 0.023 \\
\hline Entering cohort of 2014 & 0.245 & 0.246 & 0.946 \\
\hline Entering cohort of 2015 & 0.261 & 0.301 & 0.001 \\
\hline School of Engineering & 0.377 & 0.328 & 0.000 \\
\hline School of Sciences & 0.237 & 0.237 & 0.999 \\
\hline School of Business and Management & 0.355 & 0.364 & 0.475 \\
\hline School of Humanities and Social Sciences & 0.024 & 0.027 & 0.485 \\
\hline Interdisciplinary Programs & 0.007 & 0.036 & 0.000 \\
\hline
\end{tabular}

Note: The source for the population ratio is a HKUST undergraduate student profile compiled by the HKUST Student Affairs Office. The sample ratio is calculated for students who completed Parts 1, 2, and 3 of the study. Column 3 presents $p$-values from $t$-tests of whether the population proportion equals the sample proportion. 
Table A.2: Robustness - re-weighting the sample

\begin{tabular}{|c|c|c|c|c|}
\hline \multirow{3}{*}{ Sample: } & \multicolumn{4}{|c|}{ Participated in 2016 July 1st March } \\
\hline & \multicolumn{2}{|c|}{$\begin{array}{l}\text { Prior belief re: planned } \\
\text { particip. below truth }\end{array}$} & \multicolumn{2}{|c|}{$\begin{array}{l}\text { Prior belief re: planned } \\
\text { particip. above truth }\end{array}$} \\
\hline & (1) & (2) & (3) & $(4)$ \\
\hline \multicolumn{5}{|l|}{ Panel A: two-stage least squares } \\
\hline Change in belief & $\begin{array}{l}-0.468^{* *} \\
{[0.234]}\end{array}$ & $\begin{array}{l}-0.491^{* *} \\
{[0.234]}\end{array}$ & $\begin{array}{c}-0.626^{* * *} \\
{[0.248]}\end{array}$ & $\begin{array}{c}-0.685^{* * *} \\
{[0.254]}\end{array}$ \\
\hline \multicolumn{5}{|l|}{ Panel B: 1st stage on changes in belief } \\
\hline Treatment & $\begin{array}{l}4.496^{* * *} \\
{[0.546]}\end{array}$ & $\begin{array}{l}4.381^{* * *} \\
{[0.536]}\end{array}$ & $\begin{array}{c}-10.19^{* * *} \\
{[1.760]}\end{array}$ & $\begin{array}{c}-10.42^{* * *} \\
{[1.753]}\end{array}$ \\
\hline Adj. $R^{2}$ & 0.071 & 0.070 & 0.083 & 0.087 \\
\hline \multicolumn{5}{|l|}{ Panel C: reduced form } \\
\hline Treatment & $\begin{array}{l}-2.071^{*} \\
[1.172]]\end{array}$ & $\begin{array}{l}-2.113^{*} \\
{[1.139]}\end{array}$ & $\begin{array}{c}6.359^{* * * *} \\
{[1.860]}\end{array}$ & $\begin{array}{l}7.133^{* * *} \\
{[2.151]}\end{array}$ \\
\hline $\begin{array}{l}\text { Observations } \\
\text { Reweighted }\end{array}$ & $\begin{array}{l}877 \\
\text { No }\end{array}$ & $\begin{array}{l}873 \\
\text { Yes }\end{array}$ & $\begin{array}{l}364 \\
\text { No }\end{array}$ & $\begin{array}{l}361 \\
\text { Yes }\end{array}$ \\
\hline $\begin{array}{l}\text { 1st stage DV mean (control grp.) } \\
\text { 1st stage DV std. dev. (control grp.) } \\
\text { 1st stage DV mean (all) } \\
\text { 1st stage DV std. dev. (all) }\end{array}$ & $\begin{array}{l}2.274 \\
7.995 \\
5.319 \\
8.043\end{array}$ & $\begin{array}{l}2.467 \\
7.672 \\
5.393 \\
7.643\end{array}$ & $\begin{array}{c}-3.626 \\
13.22 \\
-10.84 \\
16.57\end{array}$ & $\begin{array}{c}-3.482 \\
13.09 \\
-10.58 \\
16.25\end{array}$ \\
\hline $\begin{array}{l}\text { 2nd stage DV mean (control grp.) } \\
\text { 2nd stage DV std. dev. (control grp.) } \\
\text { 2nd stage DV mean (all) } \\
\text { 2nd stage DV std. dev. (all) }\end{array}$ & $\begin{array}{l}3.222 \\
17.69 \\
1.888 \\
13.62\end{array}$ & $\begin{array}{l}3.327 \\
17.97 \\
1.921 \\
13.73\end{array}$ & $\begin{array}{l}0.712 \\
8.44 \\
4.433 \\
20.61\end{array}$ & $\begin{array}{l}1.063 \\
10.30 \\
5.898 \\
23.59\end{array}$ \\
\hline
\end{tabular}

Note: This table replicates the analyses presented in Table 5 in the main text, but reweighting the observations in the experimental sample to match the HKUST student population on gender, cohort, and the school of study within the university. 
Table A.3: Predictors of planned participation \& prior beliefs

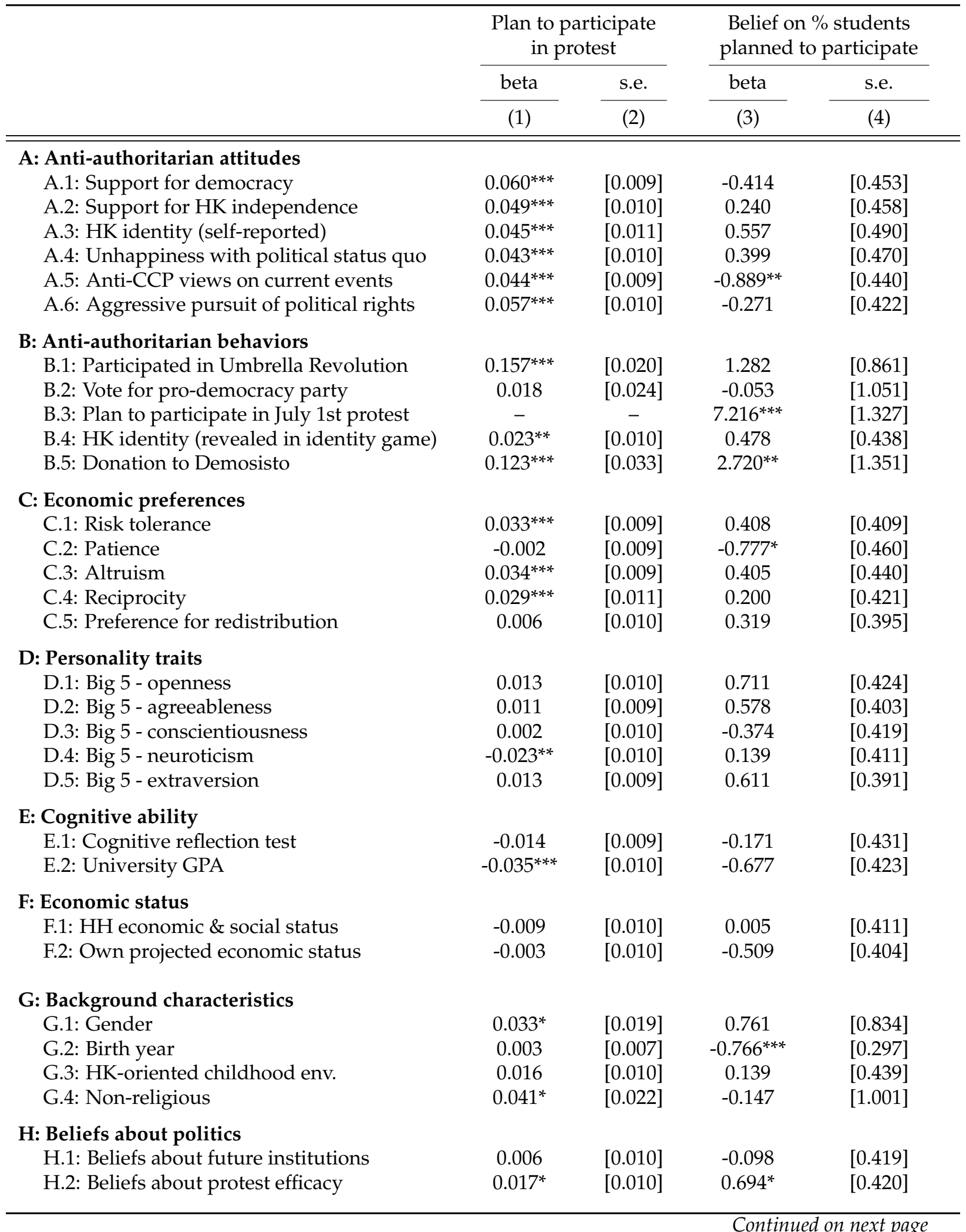




\begin{tabular}{|c|c|c|c|c|}
\hline & \multicolumn{2}{|c|}{$\begin{array}{l}\text { Plan to participate } \\
\text { in protest }\end{array}$} & \multicolumn{2}{|c|}{$\begin{array}{l}\text { Belief on \% students } \\
\text { planned to participate }\end{array}$} \\
\hline & beta & s.e. & beta & s.e. \\
\hline & (1) & (2) & (3) & (4) \\
\hline \multicolumn{5}{|l|}{ I: Beliefs about HKUST students } \\
\hline I.1: Support for democracy & $-0.027^{* * *}$ & {$[0.010]$} & 0.174 & {$[0.448]$} \\
\hline I.2: Support for HK independence & $-0.019^{* *}$ & {$[0.010]$} & 0.432 & {$[0.417]$} \\
\hline I.3: HK identity & $-0.019^{*}$ & {$[0.010]$} & 0.061 & {$[0.437]$} \\
\hline I.4: Unhappiness with political status quo & $-0.019^{*}$ & {$[0.010]$} & 0.082 & {$[0.441]$} \\
\hline I.5: Aggressive pursuit of political rights & -0.014 & {$[0.010]$} & $0.993^{* *}$ & {$[0.406]$} \\
\hline \multicolumn{5}{|l|}{ J: Social life } \\
\hline J.1: Political social network & $0.059^{* * *}$ & [0.010] & 0.674 & [0.430] \\
\hline J.2: Sociability & -0.010 & {$[0.010]$} & -0.593 & {$[0.436]$} \\
\hline \multicolumn{5}{|l|}{ K: Beliefs about close friends } \\
\hline K.1: Support for democracy & -0.016 & {$[0.010]$} & 0.246 & [0.456] \\
\hline K.2: Support for HK independence & -0.006 & {$[0.010]$} & 0.132 & [0.447] \\
\hline K.3: HK identity & $-0.017^{*}$ & {$[0.010]$} & 0.275 & [0.471] \\
\hline K.4: Unhappiness with political status quo & 0.008 & {$[0.010]$} & 0.099 & [0.466] \\
\hline K.5: Aggressive pursuit of political rights & 0.001 & {$[0.010]$} & $1.052^{* *}$ & [0.462] \\
\hline \multicolumn{5}{|l|}{ L: Media consumption } \\
\hline L.1: Frequency of news consumption & 0.013 & [0.009] & -0.046 & {$[0.395]$} \\
\hline L.2: Pro-democratic source of media & $0.021^{* *}$ & {$[0.010]$} & -0.040 & {$[0.476]$} \\
\hline \multicolumn{5}{|l|}{ M: Political interest and knowledge } \\
\hline M.1: Political interest & $0.065^{* * *}$ & {$[0.009]$} & -0.200 & {$[0.415]$} \\
\hline M.2: Political knowledge & 0.007 & [0.010] & $-1.158^{* * *}$ & [0.426] \\
\hline
\end{tabular}

Note: Table shows the predictors of planned participation and of prior beliefs regarding other survey participants' planned participation. Subjects' own plans, their priors, and the individual characteristics considered as explanatory variables were all elicited in Part 1 of the study. 